\title{
Risk of Cardiovascular Disease Due to Chronic Hepatitis C Infection: A Review
}

\author{
Ahmed Babiker ${ }^{1}$, Jean Jeudy ${ }^{\# 4}$, Seth Kligerman ${ }^{\# 4}$, Miriam Khambaty ${ }^{2,3}$, Anoop Shah ${ }^{5}$ \\ and Shashwatee Bagchi*2,3
}

\begin{abstract}
${ }^{1}$ Providence Hospital, Washington, DC, USA; ${ }^{2}$ Division of Infectious Diseases, University of Maryland School of Medicine, Baltimore, MD, USA; ${ }^{3}$ Institute of Human Virology, University of Maryland School of Medicine, Baltimore, MD, USA; ${ }^{4}$ Department of Radiology, University of Maryland School of Medicine, Baltimore, MD, USA; ${ }^{5}$ Division of Cardiology, University of Edinburgh, Little France, Edinburgh
\end{abstract}

\begin{abstract}
Hepatitis $\mathrm{C}(\mathrm{HCV})$ infection has an estimated global prevalence of $2.5 \%$, causing chronic liver disease in 170 million people worldwide. Recent data has identified HCV infection as a risk factor for subclinical and clinical cardiovascular disease $(C V D)$, but these data have been mixed and whether HCV is an independent risk factor for development of CVD remains controversial. In this review, we present the literature regarding the association of HCV with subclinical and clinical CVD and the possible underlying mechanisms leading to increased CVD among those infected with HCV. HCV infection leads to increased CVD via direct and indirect mechanisms with chronic inflammation, endothelial dysfunction and direct invasion of the arterial wall cited as possible mechanisms. Our review showed that HCV infection, particularly chronic HCV infection, appears to lead to increased subclinical CVD most consistently and potentially also to increased clinical CVD outcomes, leading to increased morbidity and mortality. Furthermore, the majority of studies evaluating the impact of HCV therapy on CVD morbidity and mortality showed an
\end{abstract}

Keywords: Hepatitis C; Cardiovascular disease; Coronary heart disease; Atherosclerosis; Cerebrovascular disease.

Abbreviations: AA, African American; AB, antibody; ACS, acute coronary syndrome; aHR, adjusted hazard ratio; AMI, acute myocardial infarction; aRR, adjusted relative risk; BMI, body mass index; CABG, coronary artery bypass graft; CAD, coronary artery disease; CCV, cerebrocardiovascular; $\mathrm{CHC}$, chronic hepatitis $\mathrm{C}$; $\mathrm{CHD}$, coronary heart disease; $\mathrm{CHF}$, congestive heart failure; $\mathrm{CI}$, confidence interval; CIMT, carotid intima media thickness; CRP, C-reactive protein; CVA, cerebrovascular accident; CVD, cardiovascular disease; DAAs, direct-acting antiviral agents; DCM, dilated cardiomyopathy; DM, diabetes mellitus; DVT, deep venous thrombosis; FMD, flow-mediated dilation; HBV, hepatitis B virus; HCM, hypertrophic cardiomyopathy; HCV, hepatitis $\mathrm{C}$ virus; HIV, human immunodeficiency virus; HLA, human leukocyte antigen; HLD, hyperlipidemia; HR, hazard ratio; ICD, implantable cardioverter defibrillator; IDCM, idiopathic DCM; IFN, interferon; IHD, ischemic heart disease; IL, interleukin; IMT, intima media thickness; IR, insulin resistance; IRR, incidence rate ratio; MA, Mexican American; MI, myocardial infarction; NASH, non-alcoholic steatohepatitis; $\mathrm{NMH}$, non-Mexican Hispanic; OR, odds ratio; $P A D$, peripheral arterial disease; $P E$, pulmonary embolism; PR, prevalence ratio; PVD, peripheral vascular disease; PVT, peripheral venous thrombosis; PWV, pulse wave velocity; RF, risk factor; RNA, ribonucleic acid; SMR, standardized mortality ratio; SVR, sustained viral response; TIA, transient ischemic attack; TNF, tumor necrosis factor; VA, Veterans Affairs; UA, unstable antigen; UK, United Kingdom; US, ultrasound; USA, United States of America. Received: 13 March 2017; Revised: 15 July 2017; Accepted: 27 July 2017 \#These two authors contributed equally to the manuscript.

*Correspondence to: Shashwatee Bagchi, Division of Infectious Diseases, University of Maryland School of Medicine, 725 West Lombard Street, N359, Baltimore, MD 21201, USA. Tel: +1-410-706-4606, Fax: +1-410-706-3243, E-mail: sbagchi@som.umaryland.edu improvement in subclinical and clinical CVD endpoints in patients who were successfully treated and achieved sustained viral suppression. These results are of particular interest following the development of new direct antiviral agents which have made HCV eradication simple and feasible for many more patients globally, and in doing so may possibly reduce CVD morbidity and mortality in those with chronic HCV infection.

Citation of this article: Babiker A, Jeudy J, Kligerman S, Khambaty M, Shah A, Bagchi S. Risk of cardiovascular disease due to chronic hepatitis $C$ infection: a review. J Clin Transl Hepatol 2017;5(4):343-362. doi: 10.14218/JCTH.2017.00021.

\section{Introduction}

Hepatitis C virus (HCV) is a single-stranded RNA virus belonging to the Flaviviridae family. ${ }^{1} \mathrm{HCV}$ infection has an estimated global prevalence of $2.5 \%$, causing chronic liver disease in 170 million people worldwide, and is the leading cause of progressive liver fibrosis, resulting in cirrhosis, liver cancer, liver failure and death. ${ }^{2,3}$ Chronic HCV (CHC) infection progresses slowly for most individuals, and patients often remain asymptomatic for decades until they develop clinically apparent liver disease resulting in delayed diagnosis. In addition to liver disease, $\mathrm{CHC}$ infection has been associated with many extrahepatic comorbidities, including cryoglobulinemia, lymphoproliferative disease, renal disease, cardiovascular disease (CVD), diabetes mellitus (DM) and insulin resistance. $^{4,5}$ Recently, HCV treatment has been transformed by the availability of oral, once-daily, and well-tolerated direct-acting antiviral agents (DAAs), which achieve $>90 \%$ sustained viral response (SVR) rates (SVR defined as an undetectable HCV RNA level 12 weeks after completing HCV treatment) among $\mathrm{CHC}$ patients.

Recent data has identified HCV infection as a risk factor for subclinical and clinical CVD. However, results of these studies are mixed and whether HCV is an independent risk factor for development of CVD remains controversial. ${ }^{6-8}$ In this review, we present the literature regarding the association of HCV with subclinical and clinical CVD and the possible underlying mechanisms leading to increased CVD among those infected with HCV. 
Babiker A. et al: Review of HCV infection and risk of CVD

\section{Methodology}

We searched PubMed for English language articles published between January 1, 1995 through December 31, 2016 using the following keywords: "hepatitis $C$, hepatitis $C$ virus, hepatitis non-A non-B, HCV, cardiovascular disease, cardiac outcomes, carotid atherosclerosis, intima-media thickness, cerebrovascular disease, stroke, cardiovascular outcomes, myocardial infarction, peripheral arterial disease (and its abbreviation PAD), and coronary artery disease. A total of 553 references were found, and of those 499 references were not selected because they were abstracts, poster presentations, correspondences or other report types, or were deemed not relevant to the scope of this review upon reading their abstracts. An additional 37 articles were added after performing ancestry and bibliography searches of all relevant articles, meta-analyses, systematic reviews, and narrative reviews on HCV and CVD. Ultimately, 91 full-length articles were reviewed. Study designs included randomized clinical trials, prospective cohorts, retrospective analyses, case-control studies, cross-sectional studies and meta-analysis.

We have presented the data from our literature review by first reporting studies that investigated possible pathogenic mechanisms of HCV on CVD in order to understand the plausible biological basis for findings reported subsequently, then presenting studies that investigated the effect of HCV infection on both subclinical and clinical outcomes of CVD, and finally presenting studies that assessed HCV infection on the myocardium. Subclinical CVD was defined as evidence of atherosclerotic disease using a surrogate measure of atherosclerosis (such as with carotid intima media thickness (CIMT), flow-mediated dilation (FMD) and pulse wave velocity (PWV)) whereas clinical CVD was defined as any clinical CVD event (such as coronary artery disease (CAD), myocardial infarction (MI), unstable antigen (UA), cerebrovascular accident (CVA), transient ischemic attack (TIA), PAD, and congestive heart failure (CHF)) (Fig. 1).

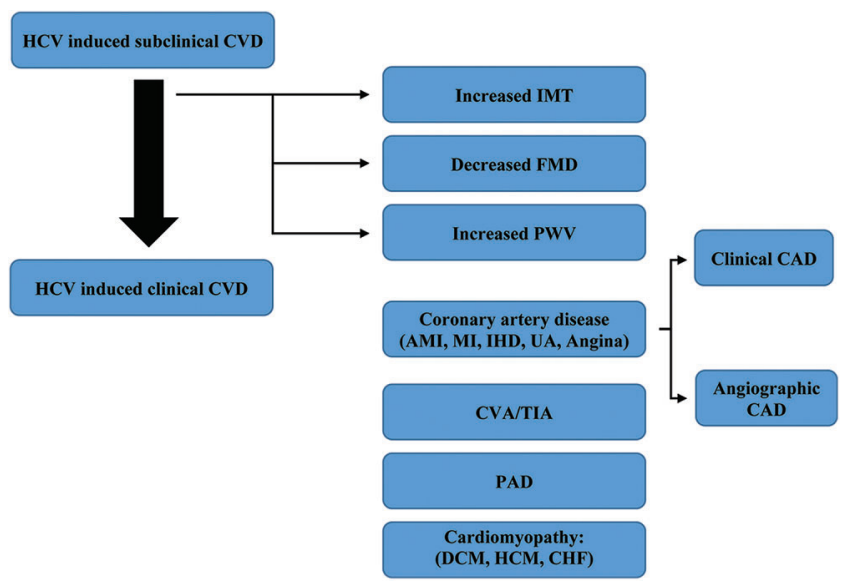

Fig. 1. Flowchart.

Abbreviations: AMI, acute myocardial infarction; CAD, coronary artery disease CVA, cerebrovascular accident; CVD, cardiovascular disease; DCM, dilated cardiomyopathy; HCM, hypertrophic cardiomyopathy; IHD, ischemic heart disease IMT, intima media thickness; FMD, flow-mediated dilation; MI, myocardial infarction; PAD, peripheral arterial disease; PWV, pulse wave velocity; UA, unstable angina.

\section{Pathogenesis}

The role of infectious agents in the development of atherosclerotic disease was first described over a century ago. ${ }^{9}$ Chronic infection with certain organisms is believed to promote the atherogenic process by inducing a systemic inflammatory state. ${ }^{10}$

HCV infection interferes with glucose and lipid metabolism, resulting in a high prevalence of insulin resistance (IR), steatosis and type 2 diabetes, which are directly associated to atherosclerosis development. However, current literature suggests that HCV infection leads to increased CVD via direct and indirect mechanisms beyond these metabolic pathways (Fig. 2). Chronic inflammation, endothelial dysfunction and direct invasion of the arterial wall have also been cited as possible mechanisms. ${ }^{8}$

$\mathrm{CHC}$ infection has been shown to result in chronic immune stimulation and increased inflammation associated with increased levels of pro-inflammatory cytokines, such as interleukin (IL)-6, tumor necrosis factor (TNF)- $\alpha$, C-reactive protein (CRP) and fibrinogen, which have all been associated with increased CVD. ${ }^{11-15}$ Adinolfi et al. ${ }^{16}$ demonstrated that the increase in pro-inflammatory cytokines among $\mathrm{HCV}$ patients was associated with a significantly higher prevalence of carotid atherosclerosis in HCV-infected patients compared to controls ( $53.7 \%$ vs. $34.3 \%, p>0.0001)$ after adjusting for presence of steatosis $(77.7 \%$ vs. $57.8 \%, p=0.0001)$. In addition, the study reported a significant association between HCV RNA level and elevated levels of serum fibrinogen and CRP, suggesting a pro-inflammatory state as the underlying mechanism independent of steatosis.

$\mathrm{HCV}$ treatment resulted in reduction of inflammatory markers and improvement in surrogate measures of endothelial function, supporting the link between $\mathrm{CHC}$ infection, inflammation, and endothelial dysfunction. Chew et al. ${ }^{17}$ demonstrated that HCV-infected patients who achieved SVR following treatment had decreased levels of SICAM-1 (a nonhepatically produced marker of endothelial dysfunction and inflammation) and SCD163 (a marker of monocyte/macrophage activation associated with the presence or burden of atherosclerotic plaque and arterial wall inflammation). In a case control study, Pateria et al. ${ }^{18}$ demonstrated improvement in vascular stiffness assessed by carotid PWV in HCVinfected patients who underwent treatment and achieved SVR (PWV $7.4 \pm 1.1 \mathrm{~m} / \mathrm{s}$ vs. $6.5 \pm 0.6 \mathrm{~m} / \mathrm{s}, p=0.04$ ).

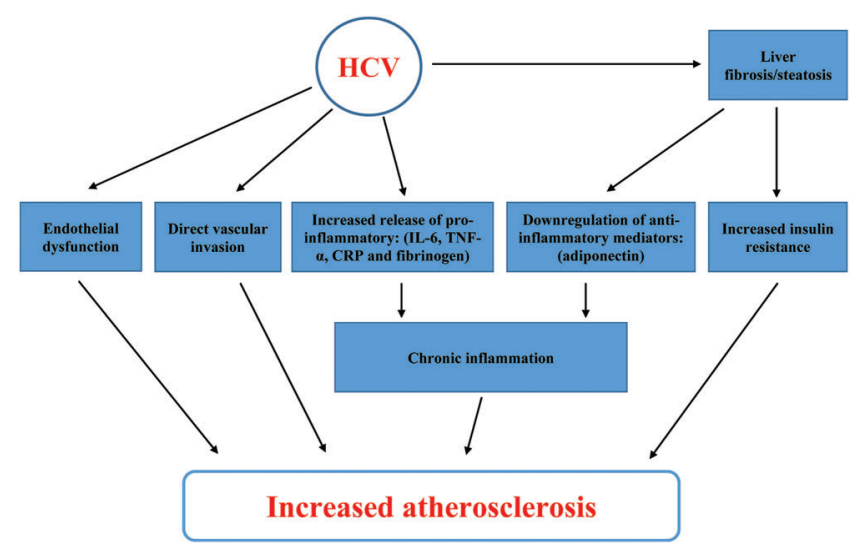

Fig. 2. Mechanism of HCV-induced CVD. 
$\mathrm{HCV}$ has been isolated from carotid plaque tissue and endothelial tissue of brain autopsy specimens taken from HCV-infected patients. ${ }^{19-21}$ Additionally, HCV RNA has been demonstrated in the myocardium of patients with myocarditis and cardiomyopathy. ${ }^{22,23}$ These interesting findings suggest a possible role for direct HCV infection in vascular and cardiac tissue, but these findings need to be reproduced in larger studies.

Not only is there an association between the presence of $\mathrm{HCV}$ and CVD but there also seems to be a causal link between the burden of HCV infection (as demonstrated by viral load or liver disease) and CVD risk. The pro-inflammatory state resulting from $\mathrm{HCV}$ infection which leads to increased CVD also promotes a pro-fibrogenic environment leading to hepatic steatosis and fibrosis. ${ }^{24}$ Petta et al. ${ }^{25}$ reported that the severity of hepatic fibrosis is directly linked to number of plaques. Adinolfi et al. ${ }^{24}$ reported that viral load and hepatic steatosis were independently associated with atherosclerosis, and Maruyama et al. ${ }^{26}$ found that patients with higher viral load and histology activity index had higher degrees of myocardial injury. Hence, increased HCV disease burden as measured by numerous indices (HCV viral load, hepatic steatosis, hepatic fibrosis) may cause patients with $\mathrm{CHC}$ to be more likely to develop HCV-associated CVD.

\section{HCV and subclinical CVD}

Several functional and anatomical surrogate markers of subclinical CVD have been investigated in HCV-infected populations to assist in predicting CVD events (Table 1). Subclinical CVD was defined as atherosclerotic disease as measured by CIMT, FMD or PWV. CIMT is a well-validated method of detecting subclinical atherosclerosis, and increased CIMT is associated with CVD risk factors, coronary atherosclerosis and CVD events. ${ }^{27}$ There were 18 studies that evaluated the effect of HCV infection on CIMT. FMD is a measure of nitric oxidemediated endothelial-dependent vasodilation measured in the brachial arteries, which is closely linked to coronary endothelial function. Lower FMD can predict CVD events and early atherosclerotic disease in the general population. ${ }^{27}$ There were two studies that evaluated the effect of HCV infection on FMD. PWV is a surrogate marker of arterial stiffness, and increased PWV has been associated with CVD and mortality. Three studies evaluated the effect of HCV infection on PWV.

Ishizaka and colleagues ${ }^{28,29}$ first reported on the atherogenic potential of HCV by demonstrating that the presence of anti-HCV antibody was associated with an increased risk of carotid plaque (odds ratio (OR): $1.92,95 \%$ confidence interval (CI): 1.56-2.38) and increased CIMT (OR: $2.85,95 \%$ CI: $2.28-3.57),{ }^{28}$ and that circulating HCV core protein was a strong independent predictor of carotid plaques (OR: 5.61, 95\% CI: 2.06-15.26; $p<0.001) .{ }^{29}$

Following these initial studies, many authors have corroborated these findings. Fukui et al. ${ }^{30}$ and Boddi et al. ${ }^{19}$ found anti-HCV antibody positivity to be an independent factor of increased CIMT, and Adinolfi et al. ${ }^{24}$ and Roed et al. ${ }^{15}$ found a statistically significant difference in CIMT and carotid plaques between HCV-infected patients and HCV-uninfected controls. Both Targher et al. ${ }^{31}$ and Tomiyama et al. ${ }^{32}$ reported increased PWV and CIMT among HCV-infected patients when compared to controls and hepatitis B virus (HBV)-infected patients. Mostafa et al. ${ }^{33}$ demonstrated that the prevalence of carotid atherosclerosis did not vary between patients with active infection compared to those with past infection who had cleared the HCV, but chronically-infected patients were shown to have increased CIMT when compared to HCVuninfected patients. More recently, Sosner et al. ${ }^{34}$ reported an increased prevalence of carotid plaque in human immunodeficiency virus (HIV)/HCV co-infected patients compared to HIV mono-infected patients (8/18 (44\%) vs. 3/22 (14\%), $p=0.04)$. All these studies further strengthen evidence for the relationship between $\mathrm{HCV}$ infection and atherosclerosis in different populations, and suggest that HCV is an independent risk factor of subclinical atherosclerosis.

Petta et al. ${ }^{25}$ found significantly greater intima media thickness (IMT) among infected patients compared with controls $(1.04 \pm 0.21$ vs. $0.90 \pm 0.16, p<0.001)$, and further demonstrated that severe hepatic fibrosis (OR: $2.177,95 \%$ CI: $1.043-4.542 ; p=0.03$ ) was independently associated with the presence of carotid plaques in multivariate logistic regression analysis.

In contrast to the above studies which demonstrated an association between $\mathrm{CHC}$ infection and carotid atherosclerosis, some other studies found no such association. Miyajima et al. ${ }^{35}$ evaluated different patient groups consisting of uninfected controls, those who had cleared HCV infection and those who had $\mathrm{CHC}$ infection, and found, surprisingly, that IMT was reduced in patients with $\mathrm{CHC}$ infection compared to the other two groups. Similarly, Bilora et al. ${ }^{36,37}$ examined the same cohort of patients with CHC infection in 2001 and 2006 and in both instances found a lower prevalence of carotid IMT and plaques in patients with chronic viral hepatitis compared to uninfected controls. Tien et al. ${ }^{38}$ found that after adjustment for cardiovascular risk factors HCV was not associated with greater CIMT in HIV/HCV co-infected and HCV monoinfected patients compared to HIV mono-infected patients and uninfected controls; similarly, Masiá et al. ${ }^{39}$ did not observe a statistically significant difference in CIMT or FMD between HIV/HCV co-infected and HIV mono-infected patients. Caliskan et al. ${ }^{40}$ found that IMT of anti-HCV-positive and anti-HCV-negative hemodialysis patients did not differ significantly as well $(0.76 \pm 0.11 \mathrm{~mm}$ vs. $0.7 \pm 0.15 \mathrm{~mm}$, $p=0.44)$. In contrast, Matsumae et al. ${ }^{41}$ and Oyake et al. ${ }^{42}$ demonstrated an association between HCV and increased PWV among dialysis patients.

In a meta-analysis by Aslam et al. ${ }^{43} \mathrm{HCV}$-infected patients were more likely to have carotid plaques than uninfected patients $(48.2 \%$ vs. $20.7 \%, p=0.05)$, but there was no statistical difference in the CIMT among the groups $(0.9 \mathrm{~mm}$ vs. $0.8 \mathrm{~mm}, p=0.3$ ). In another meta-analysis by Petta et al. ${ }^{6}$ $\mathrm{HCV}$ infection was associated with the presence of carotid plaques in eight of the nine studies, but this difference was statistically significant in only five of the studies. The pooled estimate of the effect of HCV infection on carotid plaques (OR: 2.27, 95\% CI: $1.76-2.94 ; p<0.001$ ) and IMT was significant (mean difference: $0.09,95 \% \mathrm{CI}: 0.03-0.16 ; p<0.001$ ).

Taken together, the preponderance of these data suggests that HCV infection is a risk factor for subclinical CVD, as measured by both vascular stiffness and carotid atherosclerosis.

\section{HCV and CVD}

Numerous epidemiological cohort studies have sought to delineate whether the suggested link between subclinical CVD and HCV translates to an increased risk of clinical CVD among HCV-infected patients (Table 2). We have defined clinical CVD as any of the following clinical outcomes: CAD, MI, 
Babiker A. et al: Review of HCV infection and risk of CVD

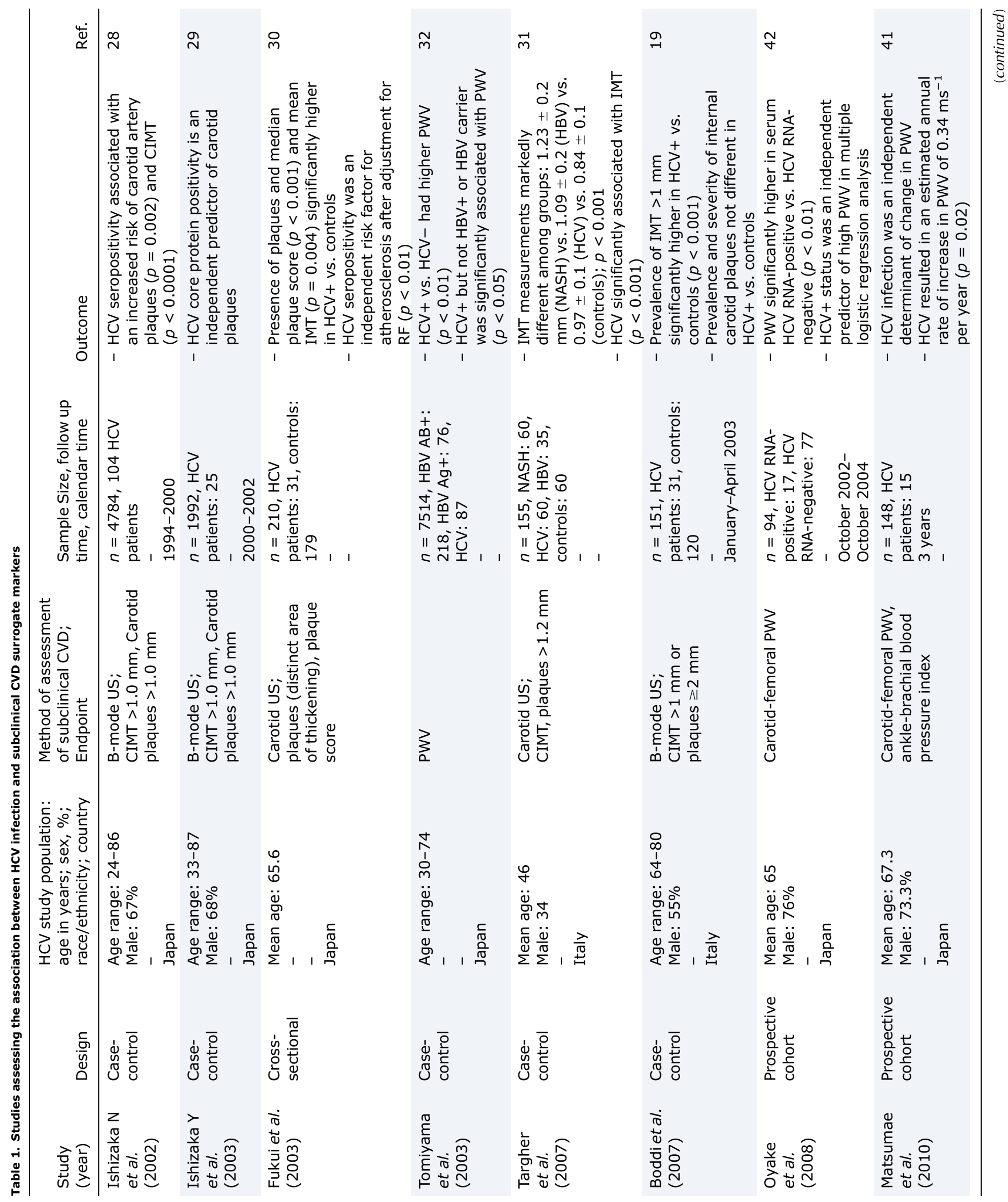


Babiker A. et al: Review of HCV infection and risk of CVD

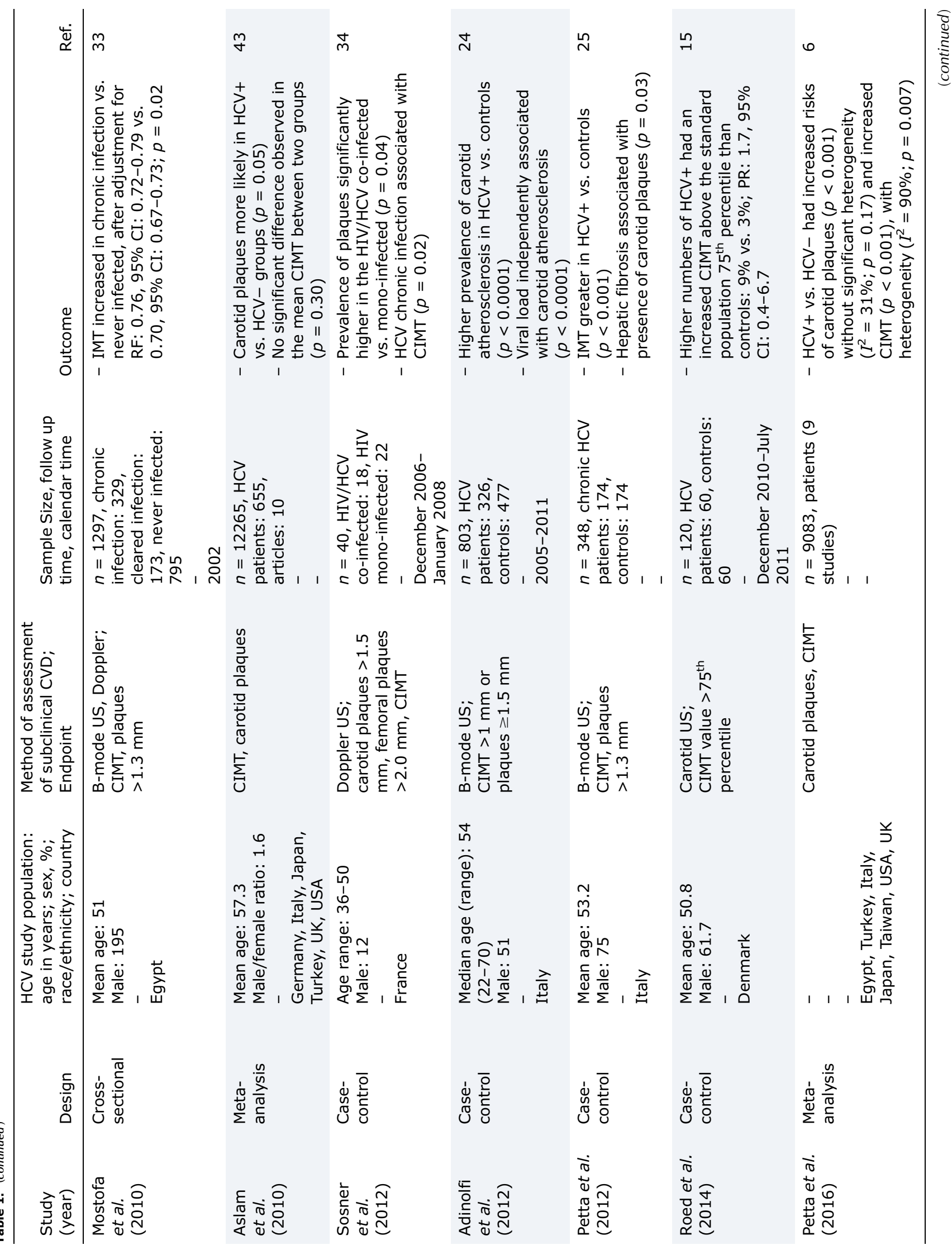


Babiker A. et al: Review of HCV infection and risk of CVD

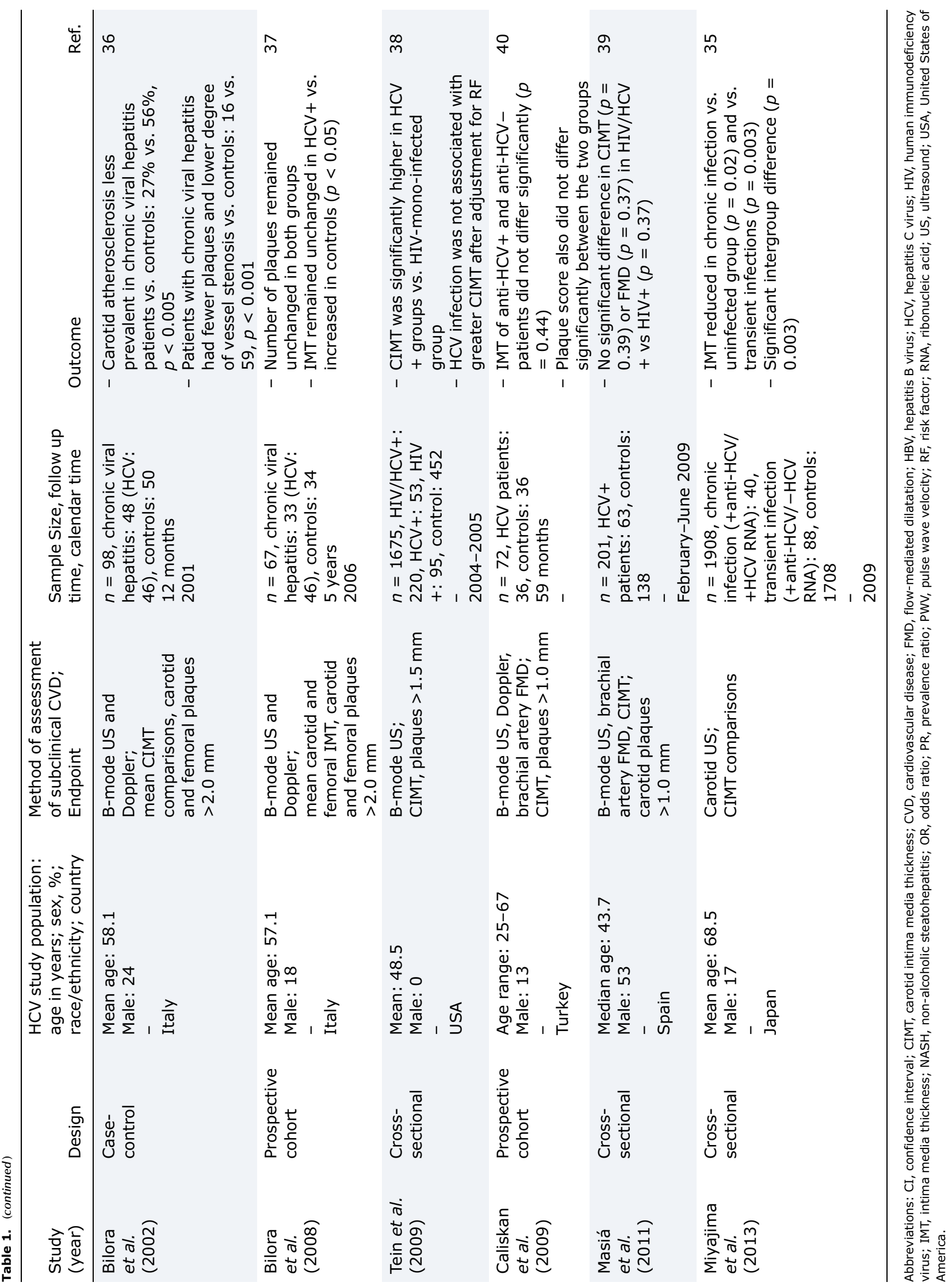


Babiker A. et al: Review of HCV infection and risk of CVD

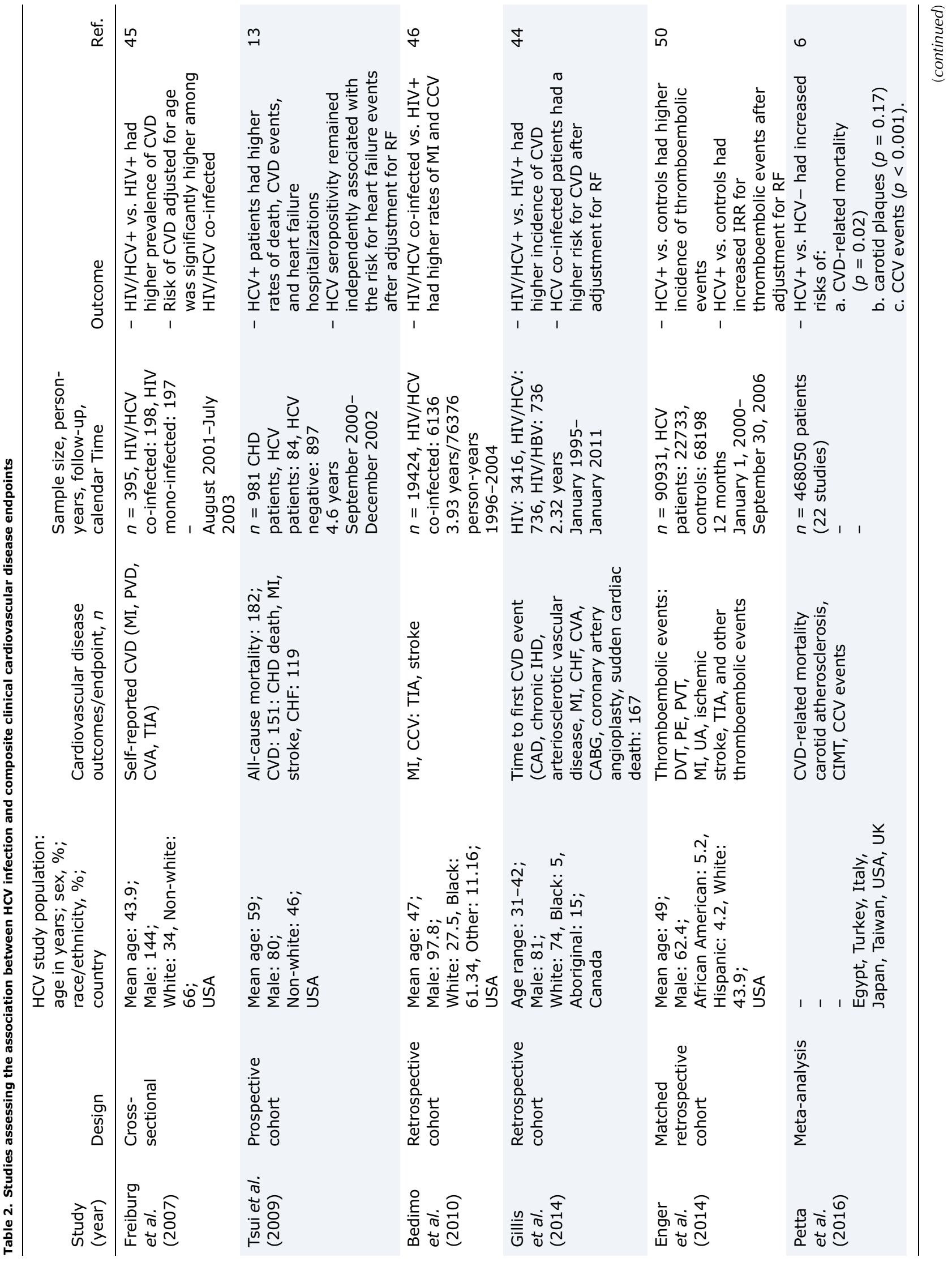


Babiker A. et al: Review of HCV infection and risk of CVD

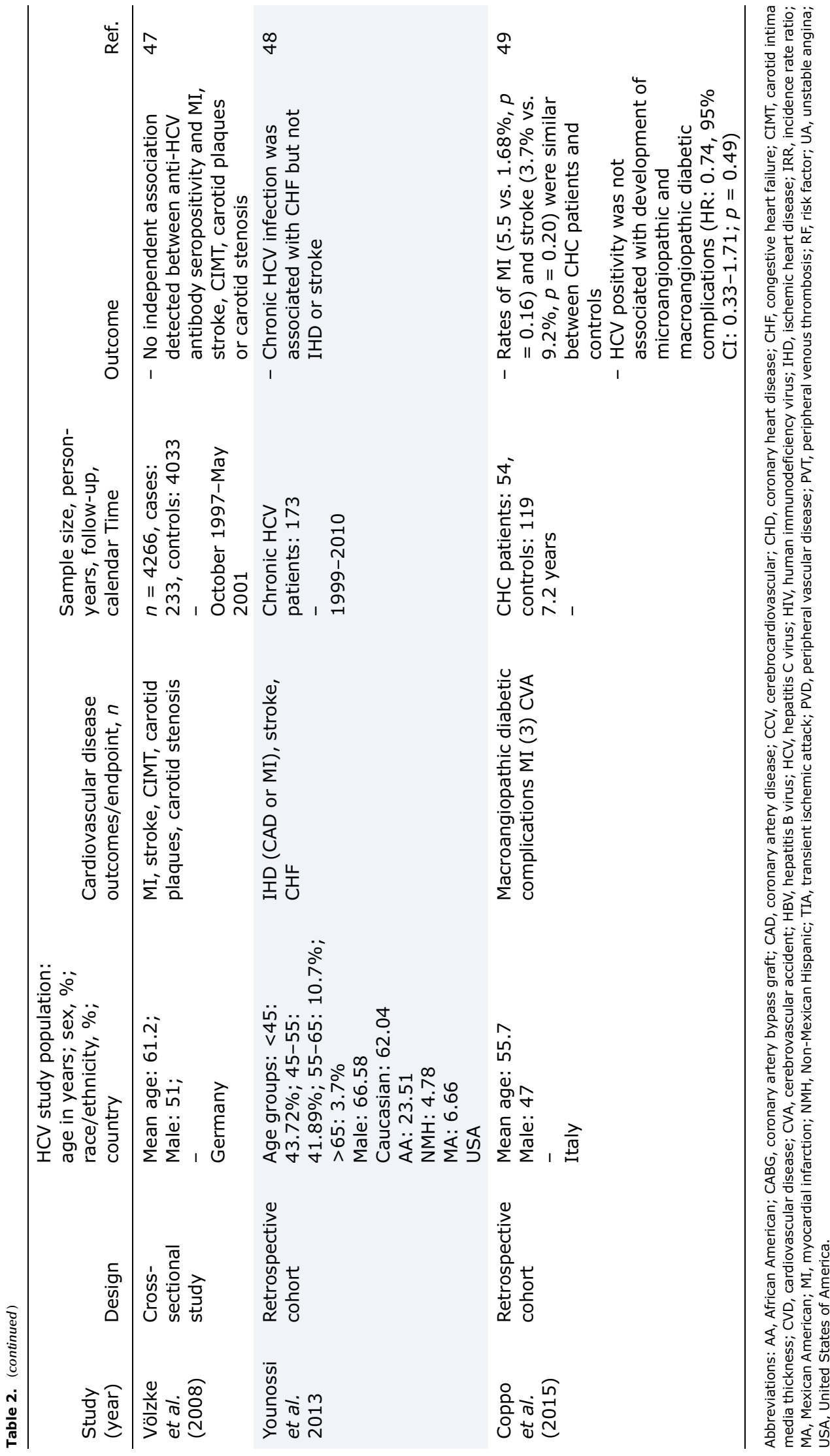


UA, CVA, TIA, PAD and CHF. Eight studies investigated the effect of HCV infection on composite clinical CVD endpoints that included two or more of the above clinical CVD events.

Tsui et al. ${ }^{13}$ assessed the rate of CVD events (cardiovascular mortality, MI, stroke, heart failure hospitalizations) among coronary heart disease (CHD) patients and found that HCV seropositive patients had higher rates of death, CVD events, and heart failure hospitalizations during followup compared to HCV seronegative patients, but after adjustment for CVD risk factors the HCV seropositivity remained independently associated with the risk for heart failure events only (hazard ratio (HR): $2.13,95 \% \mathrm{CI}: 1.19-3.80$ ).

In the Ontario HIV Treatment Network Cohort Study, Gillis et $a .^{44}$ examined the rates of CVD events (CAD, chronic ischemic heart disease (IHD) and arteriosclerotic vascular disease, MI, CHF, CVA, coronary bypass, angioplasty, or sudden cardiac death) in a large cohort of HIV mono-infected and HIV/HCV co-infected patients. There was a higher incidence of CVD events (9.62 vs. 7.59) and an elevated risk of CVD in HIV co-infected patients compared to HIV monoinfected patients (adjusted hazard ratio (aHR): $1.44,95 \%$ CI: $0.97-2.13 ; p=0.07)$. Freiburg et al. ${ }^{45}$ reported significantly increased rates of CVD and acute myocardial infarction (AMI) among HIV/HCV co-infected patients compared to HIV mono-infected patients $(11.1 \%$ vs. $2.5 \%, p<0.05)$, and after adjusting for age, HIV/HCV co-infected patients had a significantly high OR for the prevalence of CVD (adjusted OR: 4.65, 95\% CI: $1.70-12.71$ ) in the HIV Clinical Case Registry of the Veterans Affairs (VA) Center for Quality Management cohort. Bedimo et al. ${ }^{46}$ evaluated a cohort of HIV-infected patients and found that rates of AMI and cerebrovascular disease (CVA and TIA) were significantly higher in HIV/HCV co-infected patients than in HIV mono-infected patients: 4.19 vs. 3.36 events/ 1000 patient-years, respectively $(p<0.001)$ for AMI and 12.47 vs. 11.12 events/1000 patient-years, respectively $(p<0.001)$ for cerebrovascular disease.

In contrast, Völzke et $a l^{47}$ found no significant association between hepatitis $B$ or $C$ infection status and MI, stroke (CVA), CIMT, and carotid plaques or stenosis, though the CI was skewed towards an increased risk of AMI with HCV infection status. In a cohort study of patients with $\mathrm{CHC}$ infection, Younossi et al. ${ }^{48}$ found that HCV-infected patients had a significantly higher prevalence of CHF $(3.8 \%$ vs. $0.9 \%, p=$ 0.047 ) compared to controls, but there was no statistically significant difference in the prevalence of stroke, IHD, or CVD (a composite outcome including the presence of stroke, $\mathrm{CHF}$, and IHD). In multivariate analysis adjusted for age, obesity and smoking, HCV infection was significantly associated with CHF only (adjusted OR: 2.49, 95\% CI: 1.04-5.96). Coppo et al. ${ }^{49}$ found no difference in the rates of microangiopathic (neuropathy, nephropathy, retinopathy and peripheral vascular disease (PVD)) and macroangiopathic (MI and CVA) complications among HCV-positive and HCV-negative patients.

Enger et al. ${ }^{50}$ demonstrated that the proportion of patients with thromboembolic events (deep venous thrombosis (DVT), pulmonary embolism (PE), portal venous thrombosis, MI, UA, ischemic stroke, TIA, and other thromboembolic events) was more than $50 \%$ higher in the HCV-infected group compared to controls, and the incidence rate ratio (IRR) among HCVinfected patients was 1.62 (95\% CI: $1.48-1.77$ ) for any thromboembolic event after adjustment for baseline characteristics.
These studies which investigated the risk of developing clinical CVD (that included more than one CVD endpoint) conferred by $\mathrm{CHC}$ infection varied in their definitions of CVD, and therefore have reported conflicting results. Overall, they showed a trend towards a positive association between HCV and different composite endpoints of CVD, especially among the larger cohort studies, such as those conducted by Gillis et al., ${ }^{44}$ Freiberg et al., ${ }^{45}$ Bedimo et al. ${ }^{46}$ and Enger et al. ${ }^{50}$ as well as in the meta-analysis by Petta et al. ${ }^{6}$

\section{HCV and clinical CAD}

Nine studies have evaluated the effect of $\mathrm{HCV}$ infection focused only on CAD endpoints (Table 3). CAD was defined variably among the studies, and the study-specific descriptions are reported when reporting study results in the text or corresponding table. Studies that examined composite CVD endpoints were reported in the section above.

The first evidence for an association between HCV and CAD (defined as angiographic documentation of CAD of $50 \%$ stenosis or more) was reported by Vassalle et al. ${ }^{51}$, who reported an increased rate of HCV seropositivity among CAD patients and that HCV seropositivity was an independent predictor of CAD after adjusting for confounding CVD risk factors (OR: 4.2, 95\% CI: 1.4-13.0). Similar results were reproduced by Ramdeen et al. ${ }^{52}$ In a large database from the United States of America (USA), Pothineni et al. ${ }^{53}$ showed that HCV antibody positivity (OR: $1.32,95 \% \mathrm{CI}: 1.09-1.60$; $p<0.001$ ) and HCV RNA positivity (OR: $1.59,95 \% \mathrm{CI}: 1.13-$ 2.26; $p<0.001$ ) were independent risk factors for CHD events and that patients with detectable HCV RNA had a significantly higher incidence of CHD events compared to those with only HCV antibody positive but no detectable RNA (5.9\% vs. $4.7 \%, p=0.04)$.

In contrast, Arcari et al. ${ }^{54}$ found no association between $\mathrm{HCV}$ and AMI (relative risk (RR): 0.91, 95\% CI: 0.52-1.6) among young, active-duty USA military personnel. Momiyama et al. ${ }^{55}$ reported comparable rates of HCV antibody positivity among angiographically documented CAD (at least $50 \%$ stenosis in a major coronary artery) patients and controls.

Butt et al. ${ }^{56}$ performed two large studies utilizing the USA VA National Patient Care Database. In data from 1999 to 2003 including $126,926 \mathrm{HCV}$-infected and uninfected patients, the authors found that after adjusting for demographics and CVD risk factors the odds of CAD (defined by implantable cardioverter defibrillator (ICD) 9 codes for AMI, other acute and subacute forms of IHD, old MI, angina pectoris, and other forms of chronic IHD, aortocoronary bypass and percutaneous transluminal coronary angioplasty) were significantly lower in HCV-positive patients compared to HCV-negative patients (adjusted OR: 0.74, 95\% CI: 0.71-0.76). However, in the 2001 to 2006 analysis of over $80,000 \mathrm{HCV}$-infected and uninfected patients each, Butt et al. ${ }^{57}$ found that HCVinfected patients had a higher risk of CAD when compared to HCV-uninfected patients (HR: $1.27,95 \% \mathrm{CI}: 1.22-1.31$ ), despite HCV-infected patients having more favorable lipid profiles compared to controls in multivariate regression models. There were subtle differences between these two studies that may potentially explain their different results. In the first study HCV status was determined by ICD coding, while in the second study HCV status was determined by serological status. Also, the study periods were different, which may have reflected changing HCV treatment options since the 
Babiker A. et al: Review of HCV infection and risk of CVD

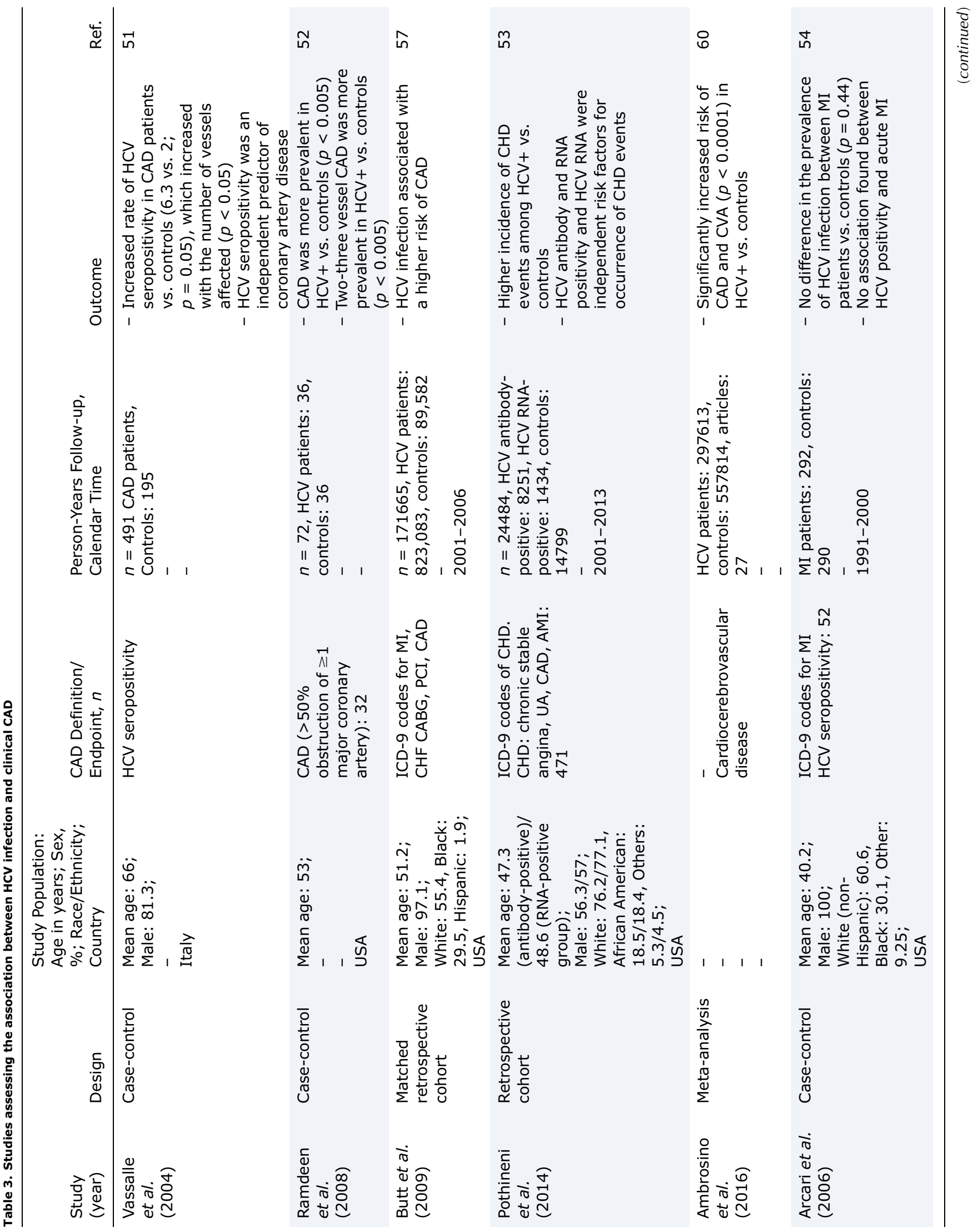


Babiker A. et al: Review of HCV infection and risk of CVD

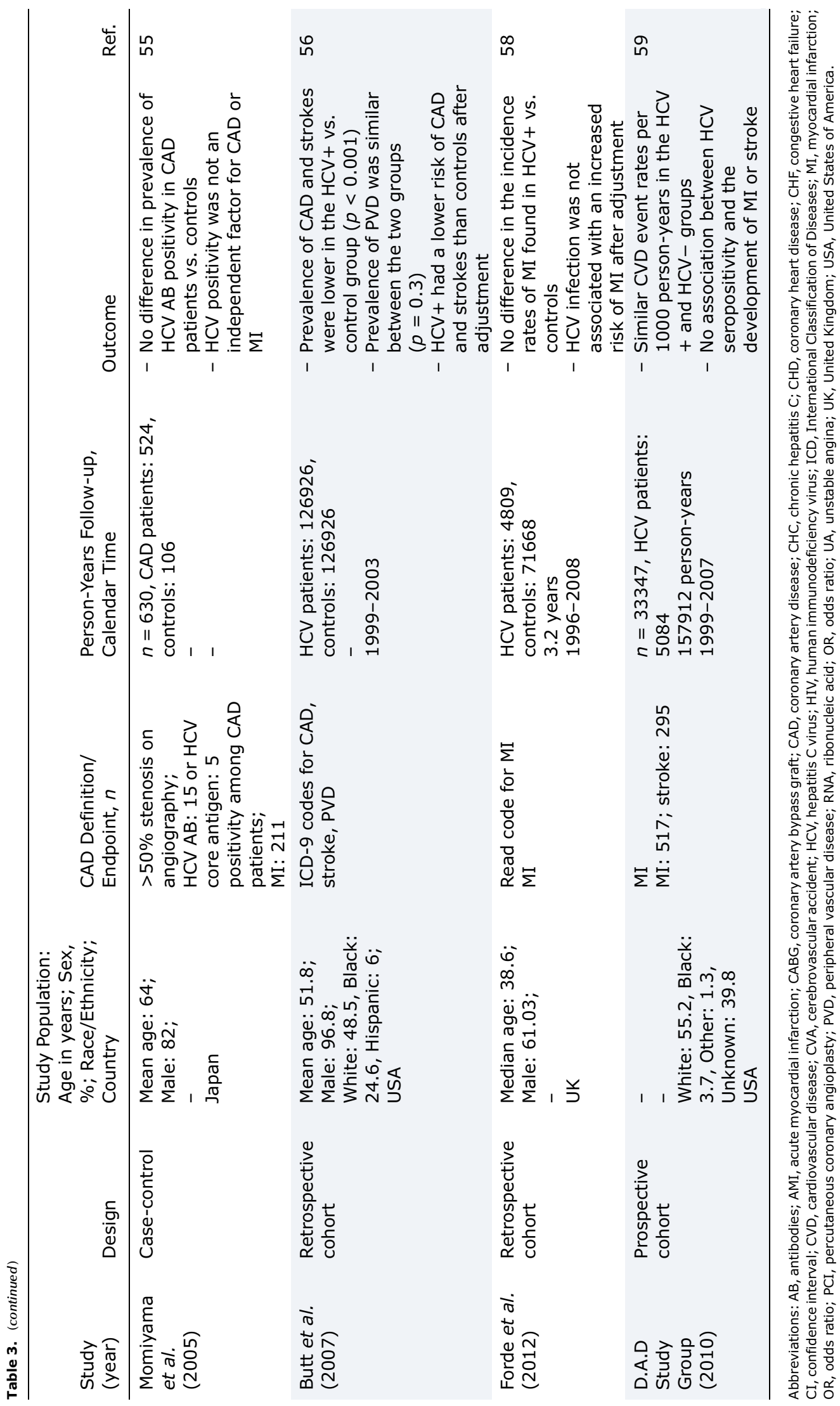


Babiker A. et al: Review of HCV infection and risk of CVD

regimen of pegylated-interferon (IFN) alpha-2a and ribavirin was approved in 2002. Other large cohorts in the United Kingdom (UK) ${ }^{58}$ and across several continents (the socalled D:A:D collaboration ${ }^{59}$ of 11 cohorts) also demonstrated no effect of HCV infection and rates of MI.

Given the mixed findings in prior studies focusing exclusively on CAD endpoints, Ambrosino et al. ${ }^{60}$ conducted a large meta-analysis to evaluate the impact of $\mathrm{CHC}$ infection on the risk of CAD. CAD was defined as the presence of at least one among the following: MI, UA, chronic stable angina, angiographic evidence of $\geq 50 \%$ stenosis in one or more coronary vessels, history of coronary revascularization, ischemic electrocardiogram according to validated criteria (major Q or QS wave, complete left-bundle branch block, small Q or QS wave, ST depression, T wave abnormality). A total of 20 studies including 273,219 HCV-infected and 473,928 HCV-uninfected patients showed a significantly increased risk of CAD associated with HCV positivity (OR: $1.382,95 \%$ CI: $1.103-1.732$; $\left.p=0.005 ; I^{2}=99 \% ; p=0.0001\right)$. Therefore, the sum of these data among various studies remains inconclusive, with several large cohort studies reporting no association between HCV infection and CAD but a few others, including the large meta-analysis cited above, finding positive associations between HCV infection and CAD.

\section{HCV and angiographic CAD}

Six studies investigated the effect of HCV on CAD based on coronary artery angiographic findings (Table 4). CAD severity was assessed using previously validated scoring systems. Both the Reardon severity scoring system ${ }^{61}$ and the Gensini score $^{62}$ visual scoring systems of CAD severity are based upon coronary angiography findings which take into account the number of vessels involved, location of the vessel, significance of the myocardial territory supplied, and degree of vessel stenosis.

Alyan et al. ${ }^{11}$ used a modified Reardon severity scoring system and demonstrated that CAD severity scores were significantly higher in the HCV seropositive group than in the control group $(p<0.001)$, and HCV seropositivity was an independent predictor for the severity of coronary atherosclerosis (OR: 2.018, 95\% CI: 1.575-2.579; $p<0.001$ ) after adjustment for age, sex, smoking, hypertension, DM, body mass index (BMI), CRP and fibrinogen. ${ }^{11}$ In patients undergoing coronary angiography for evaluation of CAD, Satapathy et $a_{1}{ }^{63}$ observed a significantly higher prevalence of CAD ( $69.8 \%$ vs. $47.6 \%, p=0.01)$, significantly higher modified Reardon's severity scores $(6.26 \pm 5.39$ vs. $2.6 \pm 3.03, p<$ 0.0005 ), and significant multivessel CAD (defined as $>50 \%$ stenosis in $\geq 2$ vessels involved; $57.1 \%$ vs. $15.9 \%, p<$ 0.0005 ) among the HCV-infected patients compared to controls. Salam et al. ${ }^{64}$ reported that HCV antibody-positive patients had more severe coronary lesions than seronegative patients among those referred for angiography. Unlike the previous studies, Pothineni et al. ${ }^{65}$ found no significant differences between HCV-infected patients and controls in the number of vessels with obstructive coronary disease, and there was no correlation between HCV RNA titers and severity of CAD as assessed by the Gensini score $(p=0.90)$.

Nonetheless, a meta-analysis by Olubamwo et al. ${ }^{66}$ concluded that HCV infection may increase the risk of occurrence and the severity of coronary atherosclerosis, which seems consistent with the results of the vast majority of studies evaluating the effect of HCV infection on severity of CAD.

\section{HCV and CVA}

There were nine studies that investigated the association between HCV infection and the development of CVA and/or mortality due to strokes. In the studies discussed below, CVA was defined by new onset neurological deficits not attributable to other causes based on ICD codes or supporting neuroimaging.

In a large prospective population-based cohort, Liao et $a l .{ }^{67}$ reported that the cumulative risk of stroke in HCVinfected patients was significantly higher than in HCV-uninfected patients (adjusted OR: 1.27, 95\% CI: 1.14-1.41). Similar results by Adinolfi et al. ${ }^{16}$ demonstrated that patients with ischemic stroke had a significantly higher prevalence of HCV infection than controls $(26.2 \%$ vs. $6.6 \%$ respectively, $p$ $=0.0001)$, and that HCV infection was an independent risk factor for stroke (OR: 2.04, 95\% CI: 1.69-2.46; $p=0.0001$ ). In a large Australian study, Lee et al. ${ }^{68}$ observed that $\mathrm{CHC}$ infection was an independent risk predictor of cerebrovascular deaths and there was an increase in cerebrovascular mortality with increasing serum HCV RNA level. Hsu et al. ${ }^{69,70}$ strengthened the relationship between $\mathrm{HCV}$ infection and CVA by showing that the incidence of stroke decreased following IFN treatment in one large retrospective and a recent prospective cohort study. Finally, while large artery atherosclerosis is certainly a risk factor for CVA among HCVinfected patients, small vessel disease may also play a role and HCV has been associated with an increase in mean arteriolar wall thickness in the deep cerebral white matter. ${ }^{71}$ In contrast to the above studies, Younossi et al. ${ }^{48}$ found no significant association between $\mathrm{HCV}$ infection and stroke (adjusted OR: $0.58,95 \% \mathrm{CI}: 0.16-2.02$ ).

In a meta-analysis by Huang et al. ${ }^{72}$ which included six studies, the authors concluded that HCV infection significantly increased the risk of stroke, and a second meta-analysis of 13 studies conducted by Ambrosino et al. ${ }^{60}$ found a significantly increased risk of cerebrovascular disease in HCV patients compared to uninfected controls (OR: 1.485 , 95\% CI: 1.079-2.044). In conclusion, the association between $\mathrm{CHC}$ infection and cerebrovascular disease has been demonstrated consistently in many population cohort studies and in two separate meta-analyses with only Younossi et al. ${ }^{48}$ reporting differing results.

\section{PAD}

There was only one study that investigated the effect of HCV infection on the development of PAD. Hsu et al. ${ }^{73}$ found that among 7,641 patients with $\mathrm{CHC}$ after adjusting for age, sex, urbanization level, and comorbidities (hypertension, HL, DM, IHD, chronic obstructive pulmonary disease, chronic kidney disease/end-stage renal disease, CVA, and acute alcoholic hepatitis), HCV-infected patients had a higher risk of developing PAD, as assessed by ICD codes for PAD, compared to age- and sex-matched controls (HR: 1.43 , 95\% CI: $1.23-$ 1.67). The risk of PAD development increased substantially with the number of comorbidities, and HCV-infected patients with four comorbidities had the highest risk of developing PAD (HR: 9.25, 95\% CI: 6.35-13.5). Further studies are needed to determine if $\mathrm{HCV}$ infection truly impacts the development of PAD. 
Babiker A. et al: Review of HCV infection and risk of CVD

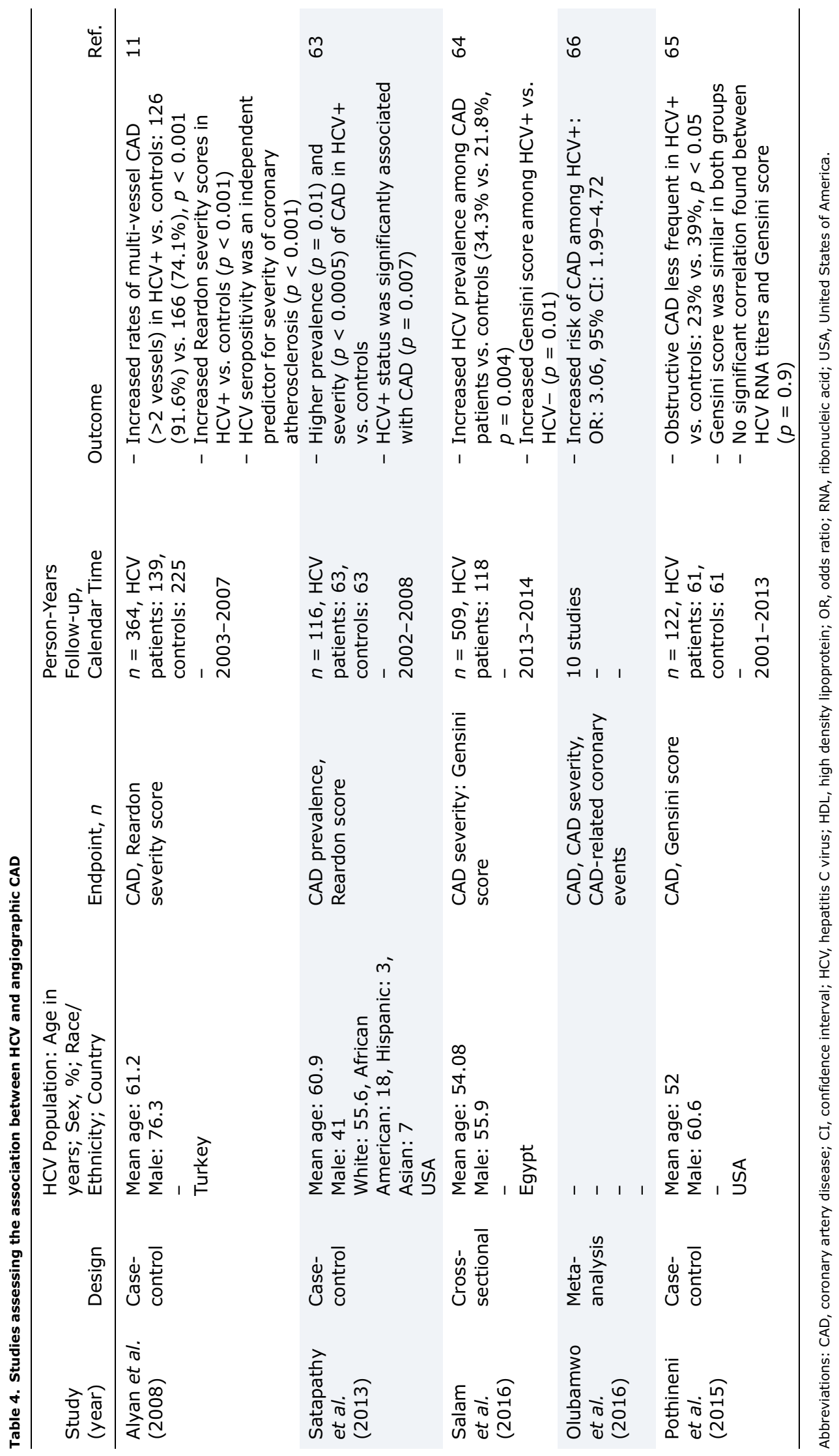




\section{HCV and cardiomyopathy}

Myocarditis and subsequent cardiomyopathy can be caused by several cardiotropic viruses. HCV has been among viruses associated with cardiomyopathy, and its effect has been hypothesized to be independent from its ischemic effects on the myocardium. ${ }^{74}$ Both Younossi et al. ${ }^{48}$ and Tsui et al. ${ }^{13}$ reported increased rates of heart failure events among patients with $\mathrm{CHC}$ compared to controls, and HCV was found to be an independent factor for $\mathrm{CHF}$ events on multivariable analysis.

Both dilated cardiomyopathy (DCM; characterized by dilation and impaired contraction of one or both ventricles) and hypertrophic cardiomyopathy (HCM; characterized by increased ventricular wall mass not caused by conditions causing volume overload) have been linked to HCV infection. ${ }^{75}$ Matsumori et al. ${ }^{23}$ reported an increased prevalence of $\mathrm{HCV}$ antibodies among patients with DCM, and detected HCV genomes within the samples of autopsied hearts from patients with myocarditis and patients with DCM or HCM. Matsumori et al. ${ }^{76}$ later found a statistically significant increased prevalence of serum-detectable HCV RNA in patients with myocarditis or cardiomyopathy compared to those with IHD. However, Dalekos et al. ${ }^{77}$ and Fujioka et al. ${ }^{78}$ evaluated patients with idiopathic DCM (IDCM) and found no association between HCV infection and IDCM. Similarly, Grumbatch et al. ${ }^{79}$ observed no association between DCM and HCV infection in patients with DCM and myocarditis compared to controls. Human leukocyte antigen (HLA) and non-HLA haplotypes have been identified in some patients with HCVassociated cardiomyopathy, suggesting a role of genetic predisposition which may differ among various patient populations, thus possibly explaining discordant results obtained in studies from Japan and Europe. ${ }^{74}$

Both Matsumori et al. ${ }^{23}$ and Teragaki et al. ${ }^{80}$ examined sera of HCM patients and matched controls and found a significantly increased prevalence of $\mathrm{HCV}$ antibodies among those with HCM. Matsumori et al. ${ }^{23}$ also identified HCV genomes within heart tissue biopsies of patients with HCM, suggesting a causal link.

\section{HCV and cardiovascular mortality}

Eight longitudinal cohort studies have evaluated mortality rates among HCV-infected patients (Table 5). Some of these studies demonstrated increased mortality rates among HCVinfected patients not only from liver related causes but also from CVD. However, other studies observed contrasting results.

Amin et al. ${ }^{81}$ found that the incidence of mortality related to CVD (as defined by ICD-10 codes for circulatory disease) as well as all-cause mortality was increased among HCV patients compared to controls, with death from CVD being the most common cause of death (standardized mortality ratio: 1.3, $95 \%$ CI: $1.2-1.5)$. Guiltinan et al. ${ }^{82}$ noted that HCV-positive blood donors had increased cardiovascular mortality compared to matched HCV-seronegative controls (HR: 2.21, 95\% CI: 1.41-3.46), but their data lacked confounding factors on CVD. In the REVEAL prospective cohort of adults with positive anti-HCV antibodies (69\% of whom had detectable HCV RNA), Lee et al. ${ }^{83}$ showed that there was an increase in both hepatic and extrahepatic mortality when compared to seronegative controls and an increased risk of death from CVD based on diagnoses reported in the
Taiwanese National Death Certification Registry. Additionally, mortality from CVD was significantly higher among patients who had detectable HCV RNA levels compared to those with undetectable HCV RNA but positive anti-HCV antibodies, suggesting antiviral therapy may have a role in decreasing HCV related CVD mortality.

HCV-related CVD mortality has also been studied among renal patients. Younossi et al. ${ }^{84}$ reported that death due to CHD was significantly increased in HCV-infected renal transplant recipients compared to $\mathrm{HCV}$-uninfected recipients. A meta-analysis by Fabrizi et al. ${ }^{85}$ in long-term dialysis patients demonstrated that anti-HCV antibody positivity was an independent and significant risk factor for death in patients on maintenance dialysis.

In contrast, Vadjic et al. ${ }^{86}$ found no association between HCV infection and CVD mortality among opioid substitution therapy registrants. Kristiansen et al. ${ }^{87}$ also observed no statistically significant increase in standardized mortality ratios due to CVD. In a meta-analysis of the three studies above involving non-renal patients, Petta et al. ${ }^{6}$ reported that the pooled estimate of the effect of HCV infection on CVD mortality was significant (OR: $1.65,95 \% \mathrm{CI}: 1.07-2.56 ; p=0.02$ ), but with significant heterogeneity $\left(I^{2}=76 \% ; p=0.02\right)$.

The data reported from the various studies, and some with large sample sizes, investigating the impact of HCV infection on cardiovascular mortality was mixed, and therefore the association remains inconclusive. However, there is a suggestion of increased CVD mortality due to HCV infection when the data are considered in total.

\section{Effect of HCV treatment on cardiovascular disease and outcomes}

Advances in the development of DAAs has resulted in dramatic improvements in HCV treatment, with ability to achieve SVR $>90 \%$ in most HCV-infected patients. ${ }^{88}$ Notably, the clinical benefits of SVR have been shown to extend beyond hepatic disease. ${ }^{89}$ Therefore, it is of great interest to determine whether these novel DAAs will further reduce CVDattributable morbidity and mortality among HCV-infected patients because demonstration of improved CVD-attributable morbidity and mortality with HCV therapy would offer powerful data supporting the role of HCV infection on CVD outcomes.

In a case-control study of 50 patients with $\mathrm{CHC}$ infection, Pateria et al. ${ }^{18}$ found significant improvement in PWV in HCVtreated patients who had achieved SVR compared to those who had not achieved SVR (PWV $7.4 \pm 1.1 \mathrm{~m} / \mathrm{s}$ vs. $6.5 \pm$ $0.6 \mathrm{~m} / \mathrm{s}, p=0.04)$. Maruyama et al. ${ }^{26}$ performed thallium201 myocardial scintigraphy on 217 patients with $\mathrm{CHC}$ infection, and $87 \%$ were found to have abnormal scintigraphy scans with liver histology activity index score and serum HCV RNA titers at baseline associated with greater abnormalities on scintigraphy scans. After interferon (IFN) therapy, scintigraphy scans improved in patients who achieved SVR.

In the French ANRS CO12 CirVir $^{90}$ prospective cohort of 1,323 CHC-infected patients treated with IFN and DAAs, the authors found that patients who achieved SVR had a lower risk of cardiovascular events, which included CHF, IHD, cardiac arrhythmia, CVA, valvular cardiomyopathy, PAD, cardiac arrest and aortic aneurysm (HR: $0.42 ; 95 \% \mathrm{CI}: 0.25-0.69$; $p=0.001$ ). Similarly, in a Scottish cohort ${ }^{91}$ of 3,385 CHCinfected patients followed up to a median of 5.3 years, 
Babiker A. et al: Review of HCV infection and risk of CVD

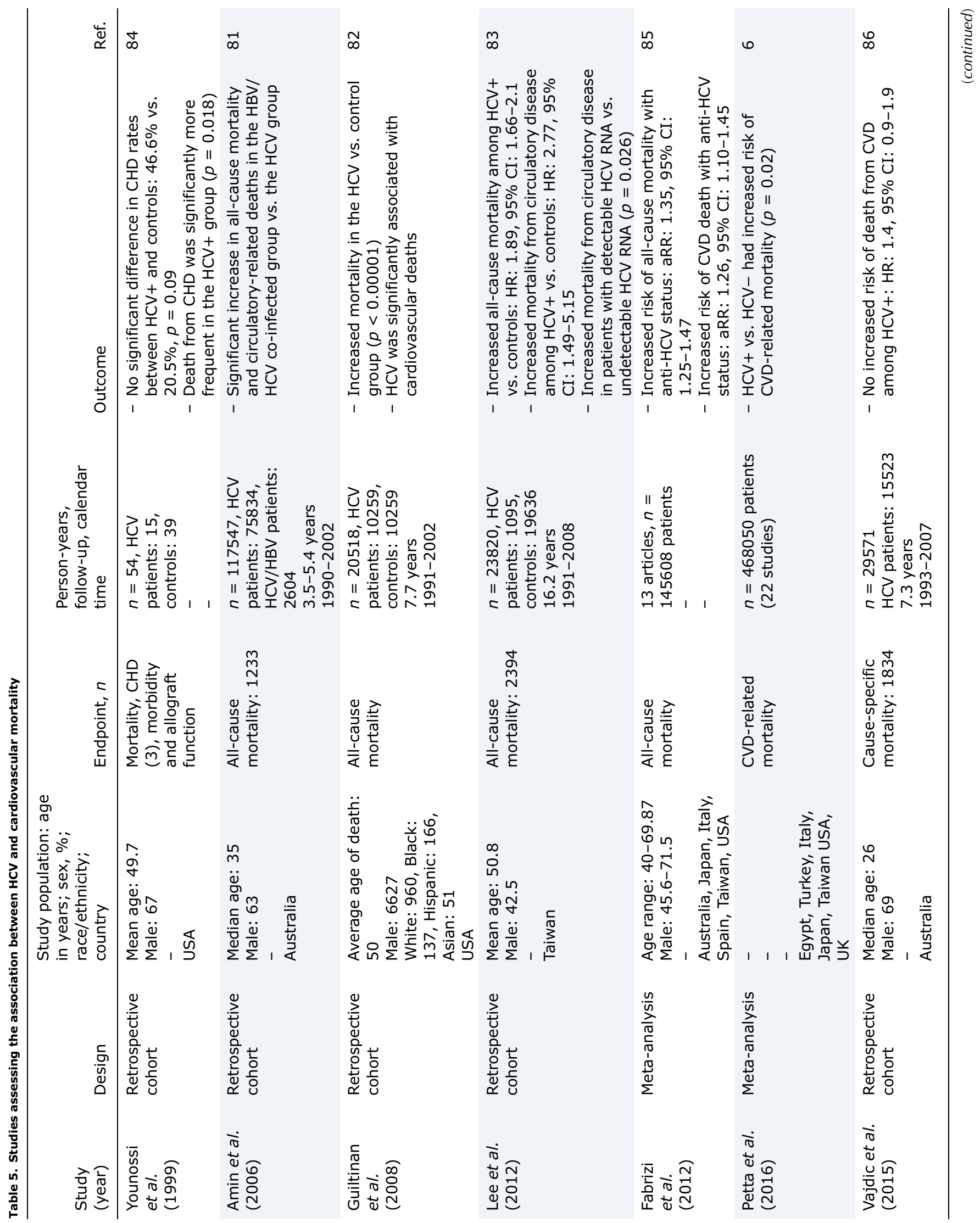


SVR was significantly associated with CVD after 7.5 years of follow-up (aHR: $3.4,95 \%$ CI: $0.5-6.1 ; p=0.019$ ).

Using data from the Taiwanese National Health Insurance Database, authors have repeatedly shown cardiovascular benefits associated with HCV clearance and achievement of SVR. Hsu et al. ${ }^{69,70}$ demonstrated decreased incidence of stroke following IFN treatment and decreased HRs for ischemic strokes and acute coronary syndrome (ACS) associated with HCV clearance after IFN-based therapy among diabetic patients. Finally, in a prospective cohort study of 12,384 patients, multivariate analyses revealed that antiviral treatment with pegylated-IFN plus ribavirin was associated with a lower risk of ACS (HR: 0.77, 95\% CI: $0.62-0.97 ; p=0.026$ ) and ischemic stroke (HR: $0.62 ; 95 \% \mathrm{CI}: 0.46-0.83 ; p=$ $0.001) .{ }^{92}$

Unlike in the Taiwanese studies, the large, multicenter, longitudinal Italian HIV/HCV co-infection cohort study (MASTER cohort) $^{93}$ found that the pooled probability of CVD and death was significantly lower in patients who achieved SVR after treatment with IFN-based therapy compared to those did not achieve SVR (log-rank $p=0.0059, p=0.04$ and $p<0.0001$, respectively). However, the significant association did not remain in the Cox regression analysis model in which achieving SVR was not associated with decreased CVD (CHD, cerebrovascular disease, chronic heart failure, or PVD). Notably, key CVD confounding factors (blood pressure, smoking, and BMI) were not available in the cohort.

The majority of the findings from studies evaluating the impact of HCV therapy on CVD morbidity and mortality showed an improvement in subclinical and clinical CVD endpoints in patients who achieved SVR. These results are of particular interest following the development of new DAAs which have revolutionized HCV treatment and made HCV eradication simple and feasible for many more patients globally, and in doing so may possibly reduce CVD morbidity and mortality in those with $\mathrm{CHC}$ infection.

\section{Discussion}

HCV infection, particularly CHC infection, appears to result in increased subclinical and clinical CVD outcomes and to lead to increased morbidity and mortality. Large well conducted studies have produced compelling yet conflicting data. There is a large and robust body of data supporting the association between HCV and subclinical CVD, as measured by CIMT, FMD and/or PWV. Many large population-based studies $^{28,29}$ as well as case controls studies ${ }^{24,30}$ have reported positive associations between $\mathrm{CHC}$ infection and increased risk of carotid atherosclerosis, whereas, in contrast, studies among smaller cohorts have not found this association in specific patient populations who represent high-risk groups for the development of atherosclerosis, such as those on hemodialysis ${ }^{40}$ or HIV co-infected patients. ${ }^{38,39}$ The association between HCV infection and subclinical CVD is further strengthened by meta-analyses which included studies with negative results and yet found significant pooled estimates of the effect of HCV on increased carotid atherscelorisis. 6,43

On the other hand, studies investigating the association between HCV infection and different clinical CVD endpoints have shown mixed results. The differences in results may be due to differences in study designs, patient populations, varying definitions of HCV positive patients (ICD codes vs. serological testing), different types of endpoints assessed 
(MI, UA, CAD, CVA, PAD) and how they were measured (angiography findings, self-reported CVD events, ICD codes), and lack of comprehensive and consistent collection of traditional cardiovascular risk factors among studies resulting in incomplete adjustments for these cardiovascular risk factors in the multivariate analyses. Among the clinical CVD endpoints, the association between HCV and CVA appears to be the strongest, with the majority of studies reporting a positive association. In addition, an association between $\mathrm{HCV}$ viral burden and increased risk of CVA has been noted. ${ }^{68,72}$

The preponderance of the data suggests an increased risk for the development of coronary artery atherosclerosis as well as an increase in the severity of CAD based on the majority of case-control studies in which HCV-infected patients underwent coronary angiography. ${ }^{11,51-53,63,64,66}$ However, it is uncertain whether the likely increased risk of coronary atherosclerosis translates to an increased risk of MI among these patients since many studies were unable to demonstrate an association between HCV infection and rates of MI. For example in the study by Forde et al., ${ }^{58} \mathrm{HCV}$ infection did not increase the risk of MI but the mean follow-up period was only 3.2 years, which may have limited the ability to detect an association given the chronic nature of atherosclerosis and the cumulative risk that eventually leads to the sentinel clinical event of MI.

Using the NHANES data Younossi et al. ${ }^{48}$ also did not find any association between HCV and CVD except with CHF, but it is important to note that in this study patients with $\mathrm{CHC}$ infection were significantly older and had a higher rate of hypertension, insulin resistance and smoking history than those without HCV infection, which may have attenuated the ability to detect such an association. Notably, the D.A.D cohort study ${ }^{59}$ that included 11 cohorts across multiple continents and which included adjustment for many though not all traditional CVD risk factors (large percentage of unknown race, rates of illicit drug use, hypertension, and DM) was unable to demonstrate an association between $\mathrm{CHC}$ infection and risk of stroke or MI.

Interestingly, while an initial study conducted by Butt et $a l .{ }^{56,57}$ reported that HCV infection (diagnosed using ICD codes) exhibited a protective effect on CVD, a subsequent follow up study using serological testing to define HCV infection reported the opposite finding that $\mathrm{HCV}$-infected patients had an increased risk of developing CVD. These two studies by the same authors highlight that differences in defining study populations may be critical in explaining some of the observed differences among studies.

Other studies such as those by Völzke et al. ${ }^{47}$ and Arcari et al. ${ }^{54}$ were significantly limited by the very small number of $\mathrm{HCV}$ cases included, and/or by a special patient population, such as young and fit active military personnel in the latter. Despite the mixed results of individual cohort and casecontrol studies evaluating the association between HCV and MI, several meta-analyses have consistently found that HCV infection increased the risk of CAD among HCV-infected patients. ${ }^{6,60,66}$

If HCV truly increased risk of developing subclinical and consequently clinical CVD outcomes, then it would be expected that this increased CVD risk should lead to increased cardiovascular mortality. Indeed, studies that investigated the association between HCV infection and CVD mortality using death registries have generally reported increased mortality among HCV-infected patients. Furthermore, in the study by Lee et al. ${ }^{83}$ which adjusted for many CVD factors and included a mean follow-up of 16 years demonstrated not only increased mortality from circulatory disease but also that HCV eradication ameliorated the CVD risk. This finding has significant implications in the current era of DAA therapy, since large numbers of patients can be treated successfully for $\mathrm{CHC}$, and suggests that HCV therapy could potentially mitigate CVD risk and outcomes among $\mathrm{CHC}$ infected patients. Numerous studies have demonstrated that higher risk $\mathrm{CHC}$-infected patients such as those with higher HCV viral load and HCV-related liver disease (hepatic steatosis and/or fibrosis) have increased CVD, ${ }^{24-26,53}$ and so the potential to reduce morbidity and mortality in these higher risk $\mathrm{CHC}$ patient groups is of great public health significance.

There were several strengths to our systematic review. First, it presented a thorough, comprehensive description of the literature on the associations between HCV and subclinical and numerous different clinical CVD outcomes (severity of $C A D, P A D$, cardiomyopathy, CVD mortality) not included in many other reviews of this topic. Second, it reported data on the effect of HCV therapy on subclinical and clinical CVD outcomes, including CVD mortality, not reported in most other reviews. Our review was limited, however, by the heterogeneous study designs, study populations and subclinical and clinical outcomes examined, as well as inconsistent and incomplete capturing of traditional CV risk factors among studies, all of which made it challenging to reconcile differences in results among them and limited our ability to make firm conclusions. Another limitation was that we did not conduct a systemic meta-analysis, but we felt that excluding so many relevant studies in the pursuit of the meta-analysis would compromise the focus of reporting comprehensive data on a heterogeneous group of surrogate measures of subclinical CVD and different clinical CVD endpoints, which necessitated including studies with very heterogeneous designs. Furthermore, the scope of our review did not account for the possible contribution of genetic variations leading to genetic predisposition of different ethnic groups and different $\mathrm{HCV}$ genotypes with $\mathrm{CHC}$ infection to CVD outcomes.

\section{Conclusions}

The current data support the assertion that $\mathrm{CHC}$ infection increases the risk of subclinical and likely clinical CVD, through a multifactorial cascade which may include direct and indirect immune and inflammatory effects, metabolic derangements and possibly direct cardiotropism exhibited by the HCV virus. There is an urgent need for translational research to delineate these proposed mechanisms for the apparent association between HCV and CVD. Additionally, more prospective cohort studies conducted in different patient populations are needed to confirm the findings of $\mathrm{HCV}$ infection and increased subclinical and clinical CVD. Furthermore, larger, well-designed therapeutic studies are critical to establish whether $\mathrm{CHC}$ truly increases CVD risk and to evaluate if HCV treatment can attenuate or even eliminate that increased CVD risk. The promise of large-scale HCV therapy ushered in by the highly efficacious and well tolerated DAAs has arrived, and therefore understanding the relationship between HCV and CVD and how this relationship is affected by HCV eradication with treatment has substantial public health implications. 


\section{Conflict of interest}

The authors have no conflict of interests related to this publication.

\section{Author contributions}

Contributed to the analysis and interpretation of data, and critical revision of the manuscript (JJ, SK, MK, AS, AB, SB), conception of the study design, collection, analysis and interpretation of data, manuscript writing and serial critical revisions of the manuscript $(A B, S B)$.

\section{References}

[1] Cooke GS, Lemoine M, Thursz M, Gore C, Swan T, Kamarulzaman A, et al. Viral hepatitis and the Global Burden of Disease: a need to regroup. J Viral Hepat 2013;20:600-601. doi: 10.1111/jvh.12123.

[2] Petruzziello A, Marigliano S, Loquercio G, Cozzolino A, Cacciapuoti C. Global epidemiology of hepatitis $C$ virus infection: An up-date of the distribution and circulation of hepatitis C virus genotypes. World J Gastroenterol 2016;22: 7824-7840. doi: 10.3748/wjg.v22.i34.7824.

[3] Chen SL, Morgan TR. The natural history of hepatitis C virus (HCV) infection. Int J Med Sci 2006;3:47-52. doi: 10.7150/ijms.3.47.

[4] Cacoub P, Gragnani L, Comarmond C, Zignego AL. Extrahepatic manifestations of chronic hepatitis C virus infection. Dig Liver Dis 2014;46 Suppl 5: S165-S173. doi: 10.1016/j.dld.2014.10.005.

[5] White DL, Ratziu V, El-Serag HB. Hepatitis C infection and risk of diabetes: a systematic review and meta-analysis. J Hepatol 2008;49:831-844. doi: 10 1016/j.jhep.2008.08.006.

[6] Petta S, Maida M, Macaluso FS, Barbara M, Licata A, Craxì A, et al. Hepatitis C virus infection is associated with increased cardiovascular mortality: a metaanalysis of observational studies. Gastroenterology 2016;150:145-155.e4. doi: 10.1053/j.gastro.2015.09.007.

[7] Wong RJ, Kanwal F, Younossi ZM, Ahmed A. Hepatitis C virus infection and coronary artery disease risk: a systematic review of the literature. Dig Dis Sci 2014;59:1586-1593. doi: 10.1007/s10620-014-3222-3.

[8] Negro F. Facts and fictions of HCV and comorbidities: steatosis, diabetes mellitus, and cardiovascular diseases. J Hepatol 2014;61:S69-S78. doi: 10.1016/j.jhep.2014.08.003.

[9] Gilbert A, Lion G. Arterites infectieuses experimentales. C R Hebd Seances Soc Biol Fil 1889;41:583-584.

[10] Shah PK. Link between infection and atherosclerosis: who are the culprits: viruses, bacteria, both, or neither? Circulation 2001;103:5-6. doi: 10. 1161/01.CIR.103.1.5

[11] Alyan O, Kacmaz F, Ozdemir O, Deveci B, Astan R, Celebi AS, et al. Hepatitis $C$ infection is associated with increased coronary artery atherosclerosis defined by modified Reardon severity score system. Circ J 2008;72:19601965. doi: 10.1253/circj.CJ-08-0459.

[12] Oliveira CP, Kappel CR, Siqueira ER, Lima VM, Stefano JT, Michalczuk MT, et al. Effects of hepatitis $C$ virus on cardiovascular risk in infected patients: a comparative study. Int J Cardiol 2013;164:221-226. doi: 10.1016/j.ijcard. 2011.07.016.

[13] Tsui JI, Whooley MA, Monto A, Seal K, Tien PC, Shlipak M. Association of hepatitis $C$ virus seropositivity with inflammatory markers and heart failure in persons with coronary heart disease: data from the Heart and Soul study. J Card Fail 2009;15:451-456. doi: 10.1016/j.cardfail.2008.12.003.

[14] Riordan SM, Skinner NA, Kurtovic J, Locarnini S, McIver CJ, Williams R, et al. Toll-like receptor expression in chronic hepatitis C: correlation with proinflammatory cytokine levels and liver injury. Inflamm Res 2006;55:279285. doi: 10.1007/s00011-006-0082-0.

[15] Roed T, Kristoffersen US, Knudsen A, Wiinberg N, Lebech AM, Almdal T, et al. Increased prevalence of coronary artery disease risk markers in patients with chronic hepatitis C-a cross-sectional study. Vasc Health Risk Manag 2014; 10:55-62. doi: 10.2147/VHRM.S53557.

[16] Adinolfi LE, Restivo L, Guerrera B, Sellitto A, Ciervo A, Iuliano N, et al. Chronic HCV infection is a risk factor of ischemic stroke. Atherosclerosis 2013:231:22-26. doi: 10.1016/j.atherosclerosis.2013.08.003.

[17] Chew KW, Hua L, Bhattacharya D, Butt AA, Bornfleth L, Chung RT, et al. The effect of hepatitis $C$ virologic clearance on cardiovascular disease biomarkers in human immunodeficiency virus/hepatitis $C$ virus coinfection. Open Forum Infect Dis 2014;1: ofu104. doi: 10.1093/ofid/ofu104.

[18] Pateria P, Jeffrey GP, MacQuillan G, Speers D, Ching H, Chinnaratha MA, et al. The association between chronic hepatitis $C$ infection and cardiovascular risk. Intern Med J 2016;46:63-70. doi: 10.1111/imj.12936.
[19] Boddi M, Abbate R, Chellini B, Giusti B, Solazzo V, Soft F, et al. HCV infection facilitates asymptomatic carotid atherosclerosis: preliminary report of $\mathrm{HCV}$ RNA localization in human carotid plaques. Dig Liver Dis 2007;39 Suppl 1 : S55-S60. doi: 10.1016/S1590-8658(07)80012-0.

[20] Boddi M, Abbate R, Chellini B, Giusti B, Giannini C, Pratesi G, et al. Hepatitis C virus RNA localization in human carotid plaques. J Clin Virol 2010;47:72-75. doi: 10.1016/j.jcv.2009.10.005.

[21] Fletcher NF, Wilson GK, Murray ], Hu K, Lewis A, Reynolds GM, et al. Hepatitis $C$ virus infects the endothelial cells of the blood-brain barrier. Gastroenterology 2012;142:634-643.e6. doi: 10.1053/j.gastro.2011.11.028.

[22] Frustaci A, Calabrese F, Chimenti C, Pieroni M, Thiene G, Maseri A. Lone hepatitis $C$ virus myocarditis responsive to immunosuppressive therapy Chest 2002;122:1348-1356. doi: 10.1378/chest.122.4.1348.

[23] Matsumori A, Ohashi N, Nishio R, Kakio T, Hara M, Furukawa Y, et al. Apical hypertrophic cardiomyopathy and hepatitis C virus infection. Jpn Circ J 1999 ; 63:433-438. doi: 10.1253/jcj.63.433.

[24] Adinolfi LE, Restivo L, Zampino R, Guerrera B, Lonardo A, Ruggiero L, et al. Chronic HCV infection is a risk of atherosclerosis. Role of HCV and HCV related steatosis. Atherosclerosis 2012;221:496-502. doi: $10.1016 / \mathrm{j}$.atherosclerosis.2012.01.051.

[25] Petta S, Torres D, Fazio G, Cammà C, Cabibi D, Di Marco V, et al. Carotid atherosclerosis and chronic hepatitis $\mathrm{C}$ : a prospective study of risk associations. Hepatology 2012;55:1317-1323. doi: 10.1002/hep.25508.

[26] Maruyama S, Koda M, Oyake N, Sato H, Fujii $Y$, Horie $Y$, et al. Myocardia injury in patients with chronic hepatitis $C$ infection. J Hepatol 2013;58:1115. doi: $10.1016 / j$.jhep.2012.07.045.

[27] Tardif JC, Heinonen T, Orloff D, Libby P. Vascular biomarkers and surrogates in cardiovascular disease. Circulation 2006;113:2936-2942. doi: 10. 1161/CIRCULATIONAHA.105.598987.

[28] Ishizaka N, Ishizaka Y, Takahashi E, Tooda Ei, Hashimoto H, Nagai R, et al. Association between hepatitis $\mathrm{C}$ virus seropositivity, carotid-artery plaque, and intima-media thickening. Lancet 2002;359:133-135. doi: 10 . 1016/S0140-6736(02)07339-7.

[29] Ishizaka $Y$, Ishizaka $N$, Takahashi $E$, Unuma $T$, Tooda $E$, Hashimoto $H$, et al. Association between hepatitis $\mathrm{C}$ virus core protein and carotid atherosclerosis. Circ J 2003;67:26-30. doi: 10.1253/circj.67.26.

[30] Fukui M, Kitagawa Y, Nakamura N, Yoshikawa T. Hepatitis C virus and atherosclerosis in patients with type 2 diabetes. JAMA 2003;289:1245-1246. doi: 10.1001/jama.289.10.1245-b.

[31] Targher G, Bertolini L, Padovani R, Rodella S, Arcaro G, Day C. Differences and similarities in early atherosclerosis between patients with non-alcoholic steatohepatitis and chronic hepatitis B and C. J Hepatol 2007;46:11261132. doi: $10.1016 /$ j.jhep.2007.01.021.

[32] Tomiyama H, Arai T, Hirose K, Hori S, Yamamoto Y, Yamashina A. Hepatitis C virus seropositivity, but not hepatitis $\mathrm{B}$ virus carrier or seropositivity, associated with increased pulse wave velocity. Atherosclerosis 2003;166:401403. 10.1016/S0021-9150(02)00388-X.

[33] Mostafa A, Mohamed MK, Saeed M, Hasan A, Fontanet A, Godsland I, et al. Hepatitis $C$ infection and clearance: impact on atherosclerosis and cardiometabolic risk factors. Gut 2010;59:1135-1140. doi: 10.1136/gut.2009. 202317.

[34] Sosner P, Wangermez M, Chagneau-Derrode C, Le Moal G, Silvain C. Atherosclerosis risk in HIV-infected patients: the influence of hepatitis $C$ virus co-infection. Atherosclerosis 2012;222:274-277. doi: 10.1016/j.atherosclerosis.2012.02.027

[35] Miyajima I, Kawaguchi T, Fukami A, Nagao Y, Adachi H, Sasaki S, et al. Chronic HCV infection was associated with severe insulin resistance and mild atherosclerosis: a population-based study in an HCV hyperendemic area. J Gastroenterol 2013;48:93-100. doi: 10.1007/s00535-012-0610-3.

[36] Bilora F, Rinaldi R, Boccioletti V, Petrobelli F, Girolami A. Chronic viral hepatitis: a prospective factor against atherosclerosis. A study with echo-colo Doppler of the carotid and femoral arteries and the abdominal aorta. Gastroenterol Clin Biol 2002;26:1001-1004

[37] Bilora F, Campagnolo E, Rinaldi R, Rossato A, Arzenton M, Petrobelli F. Carotid and femoral atherosclerosis in chronic hepatitis $\mathrm{C}$ : a 5-year follow-up. Angiology 2009;59:717-720. doi: 10.1177/0003319707311536.

[38] Tien PC, Schneider MF, Cole SR, Cohen MH, Glesby MJ, Lazar J, et al. Association of hepatitis $\mathrm{C}$ virus and HIV infection with subclinical atherosclerosis in the women's interagency HIV study. AIDS 2009;23:1781-1784. doi: 10 . 1097/QAD.0b013e32832d7aa8.

[39] Masiá M, Padilla S, Robledano C, Ramos JM, Gutiérrez F. Evaluation of endothelial function and subclinical atherosclerosis in association with hepatitis $C$ virus in HIV-infected patients: a cross-sectional study. BMC Infect Dis 2011 11:265. doi: 10.1186/1471-2334-11-265.

[40] Caliskan $\mathrm{Y}$, Oflaz $\mathrm{H}$, Pusuroglu $\mathrm{H}$, Boz H, Yazici $\mathrm{H}$, Tamer $\mathrm{S}$, et al. Hepatitis $\mathrm{C}$ virus infection in hemodialysis patients is not associated with insulin resistance, inflammation and atherosclerosis. Clin Nephrol 2009;71:147-157. doi: $10.5414 /$ CNP71147. 
[41] Matsumae T, Ueda K, Abe $Y$, Nishimura S, Murakami G, Saito T. What factors accelerate aortic stiffening in hemodialysis patients? An observational study. Hypertens Res 2010;33:243-249. doi: 10.1038/hr.2009.219.

[42] Oyake N, Shimada T, Murakami $Y$, Ishibashi $Y$, Satoh $H$, Suzuki K, et al. Hepatitis $C$ virus infection as a risk factor for increased aortic stiffness and cardiovascular events in dialysis patients. J Nephrol 2008;21:345-353.

[43] Aslam F, Alam M, Lakkis NM. Hepatitis C and carotid atherosclerosis: a retrospective analysis. Atherosclerosis $2010 ; 209: 340-343$. doi: $10.1016 / j$.atherosclerosis.2009.10.006.

[44] Gillis J, Smieja M, Cescon A, Rourke SB, Burchell AN, Cooper C, et al. Risk of cardiovascular disease associated with $\mathrm{HCV}$ and $\mathrm{HBV}$ coinfection among antiretroviral-treated HIV-infected individuals. Antivir Ther 2014;19:309-317. doi: 10.3851/IMP2724.

[45] Freiberg MS, Cheng DM, Kraemer KL, Saitz R, Kuller LH, Samet JH. The association between hepatitis $C$ infection and prevalent cardiovascular disease among HIV-infected individuals. AIDS 2007;21:193-197. doi: 10. 1097/QAD.0b013e3280118a0d.

[46] Bedimo R, Westfall AO, Mugavero M, Drechsler H, Khanna N, Saag M. Hepatitis $C$ virus coinfection and the risk of cardiovascular disease among HIVinfected patients. HIV Med 2010;11:462-468. doi: 10.1111/j.1468-1293. 2009.00815.x.

[47] Völzke H, Schwahn C, Wolff B, Mentel R, Robinson DM, Kleine V, et al. Hepatitis $B$ and $C$ virus infection and the risk of atherosclerosis in a general population. Atherosclerosis $2004 ; 174: 99-103$. doi: $10.1016 / j$.atherosclerosis.2004.01.010.

[48] Younossi ZM, Stepanova M, Nader F, Younossi Z, Elsheikh E. Associations of chronic hepatitis $\mathrm{C}$ with metabolic and cardiac outcomes. Aliment Pharmacol Ther 2013;37:647-652. doi: 10.1111/apt.12234.

[49] Coppo C, Bonfanti D, Bo S, Giordanino C, Gallo M, Cococcia S, et al. Risk of microangiopathy in type 2 diabetes mellitus patients with or without chronic hepatitis C: Results of a retrospective long-term controlled cohort study. Dig Liver Dis 2015;47:405-410. doi: 10.1016/j.dld.2015.01.157.

[50] Enger C, Forssen UM, Bennett D, Theodore D, Shantakumar S, McAfee A. Thromboembolic events among patients with hepatitis $C$ virus infection and cirrhosis: a matched-cohort study. Adv Ther 2014;31:891-903. doi: 10.1007/s12325-014-0138-4.

[51] Vassalle C, Masini S, Bianchi F, Zucchelli GC. Evidence for association between hepatitis $C$ virus seropositivity and coronary artery disease. Heart 2004;90:565-566. doi: 10.1136/hrt.2003.018937.

[52] Ramdeen N, Aronow WS, Chugh S, Asija A. Patients undergoing coronary angiography because of chest pain with hepatitis $C$ virus seropositivity have a higher prevalence of obstructive coronary artery disease than a control group. Arch Med Sci 2008;4:452-454.

[53] Pothineni NV, Delongchamp R, Vallurupalli S, Ding Z, Dai Y, Hagedorn $\mathrm{CH}$, et al. Impact of hepatitis $C$ seropositivity on the risk of coronary heart disease events. Am J Cardiol 2014;114:1841-1845. doi: 10.1016/j.amjcard.2014 09.020.

[54] Arcari CM, Nelson KE, Netski DM, Nieto FJ, Gaydos CA. No association between hepatitis $C$ virus seropositivity and acute myocardial infarction. Clin Infect Dis 2006;43:e53-e56. doi: 10.1086/507031.

[55] Momiyama Y, Ohmori R, Kato R, Taniguchi H, Nakamura H, Ohsuzu F. Lack of any association between persistent hepatitis $B$ or $C$ virus infection and coronary artery disease. Atherosclerosis 2005;181:211-213. doi: 10.1016/j. atherosclerosis.2005.02.027.

[56] Butt AA, Khan UA, McGinnis KA, Skanderson M, Kent Kwoh C. Co-morbid medical and psychiatric illness and substance abuse in HCV-infected and uninfected veterans. J Viral Hepat 2007;14:890-896. doi: 10.1111/j. 1365-2893.2007.00885.x.

[57] Butt AA, Xiaoqiang W, Budoff M, Leaf D, Kuller LH, Justice AC. Hepatitis C virus infection and the risk of coronary disease. Clin Infect Dis 2009;49:225232. doi: $10.1086 / 599371$.

[58] Forde KA, Haynes K, Troxel AB, Trooskin S, Osterman MT, Kimmel SE, et al. Risk of myocardial infarction associated with chronic hepatitis $C$ virus infection: a population-based cohort study. J Viral Hepat 2012;19:271-277. doi: 10.1111/j.1365-2893.2011.01545.x

[59] Data Collection on Adverse Events of Anti-HIV Drugs (D:A:D) Study Group, Weber R, Sabin C, Reiss P, de Wit S, Worm SW, et al. HBV or HCV coinfections and risk of myocardial infarction in HIV-infected individuals: the D:A:D Cohort Study. Antivir Ther 2010;15:1077-1086. doi: 10.3851/IMP1681.

[60] Ambrosino P, Lupoli R, Di Minno A, Tarantino L, Spadarella G, Tarantino P, et al. The risk of coronary artery disease and cerebrovascular disease in patients with hepatitis C: A systematic review and meta-analysis. Int J Cardiol 2016;221:746-754. doi: 10.1016/j.ijcard.2016.06.337.

[61] Reardon MF, Nestel PJ, Craig IH, Harper RW. Lipoprotein predictors of the severity of coronary artery disease in men and women. Circulation 1985; 71:881-888. doi: 10.1161/01.CIR.71.5.881.

[62] Gensini GG. A more meaningful scoring system for determining the severity of coronary heart disease. Am J Cardiol 1983;51:606. doi: 10.1016/S00029149(83)80105-2.
[63] Satapathy SK, Kim YJ, Kataria A, Shifteh A, Bhansali R, Cerulli MA, et al. Higher prevalence and more severe coronary artery disease in hepatitis $C$ virus-infected patients: a case control study. J Clin Exp Hepatol 2013;3:186191. doi: 10.1016/j.jceh.2013.05.004.

[64] Salam RA, Nabil B, Saber M, AbdelWahab HA, Saber T. Prevalence of hepatitis $C$ virus seropositivity and its impact on coronary artery disease among Egyptian patients referred for coronary angiography. Cardiol Res Pract 2016; 2016:1623197. doi: 10.1155/2016/1623197.

[65] Pothineni NV, Rochlani Y, Vallurupalli S, Kovelamudi S, Ahmed Z, Hakeem A, et al. Comparison of angiographic burden of coronary artery disease in patients with versus without hepatitis C infection. Am J Cardiol 2015;116: 1041-1044. doi: 10.1016/j.amjcard.2015.06.035.

[66] Olubamwo OO, Aregbesola AO, Miettola J, Kauhanen J, Tuomainen TP. Hepatitis $\mathrm{C}$ and risk of coronary atherosclerosis - A systematic review. Public Health 2016;138:12-25. doi: 10.1016/j.puhe.2016.04.005.

[67] Liao CC, Su TC, Sung FC, Chou WH, Chen TL. Does hepatitis C virus infection increase risk for stroke? A population-based cohort study. PLoS One 2012;7: e31527. doi: 10.1371/journal.pone.0031527.

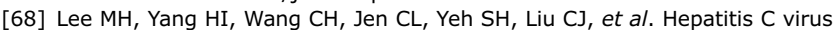
infection and increased risk of cerebrovascular disease. Stroke 2010;41: 2894-2900. doi: 10.1161/STROKEAHA.110.598136.

[69] Hsu CS, Kao JH, Chao YC, Lin HH, Fan YC, Huang C], et al. Interferon-based therapy reduces risk of stroke in chronic hepatitis $C$ patients: a populationbased cohort study in Taiwan. Aliment Pharmacol Ther 2013;38:415-423. doi: 10.1111/apt.12391.

[70] Hsu YC, Lin JT, Ho HJ, Kao YH, Huang YT, Hsiao NW, et al. Antiviral treatment for hepatitis $C$ virus infection is associated with improved renal and cardiovascular outcomes in diabetic patients. Hepatology 2014;59:1293-1302. doi: $10.1002 /$ hep. 26892 .

[71] Morgello S, Murray J, Van Der Elst S, Byrd D. HCV, but not HIV, is a risk factor for cerebral small vessel disease. Neurol Neuroimmunol Neuroinflamm 2014;1:e27. doi: 10.1212/NXI.0000000000000027.

[72] He Huang, Kang R, Zhao Z. Hepatitis C virus infection and risk of stroke: a systematic review and meta-analysis. PLoS One 2013;8:e81305. doi: 10. 1371/journal.pone.0081305.

[73] Hsu YH, Muo CH, Liu CY, Tsai WC, Hsu CC, Sung FC, et al. Hepatitis C virus infection increases the risk of developing peripheral arterial disease: a 9year population-based cohort study. J Hepatol 2015;62:519-525. doi: 10. 1016/j.jhep.2014.09.022.

[74] Sanchez MJ, Bergasa NV. Hepatitis C associated cardiomyopathy: potential pathogenic mechanisms and clinical implications. Med Sci Monit 2008;14: RA55-RA63

[75] Richardson P, McKenna W, Bristow M, Maisch B, Mautner B, O'Connell J, et al. Report of the 1995 World Health Organization/International Society and Federation of Cardiology Task Force on the Definition and Classification of cardiomyopathies. Circulation 1996;93:841-842. doi: 10.1161/01.CIR. 93.5.841.

[76] Matsumori A, Matoba Y, Sasayama S. Dilated cardiomyopathy associated with hepatitis C virus infection. Circulation 1995;92:2519-2525. doi: 10. 1161/01.CIR.92.9.2519.

[77] Dalekos GN, Achenbach K, Christodoulou D, Liapi GK, Zervou EK, Sideris DA, et al. Idiopathic dilated cardiomyopathy: lack of association with hepatitis C virus infection. Heart 1998;80:270-275. doi: 10.1136/hrt.80.3.270.

[78] Fujioka S, Kitaura $Y$, Ukimura A, Deguchi $H$, Kawamura $K$, Isomura $T$, et al. Evaluation of viral infection in the myocardium of patients with idiopathic dilated cardiomyopathy. J Am Coll Cardiol 2000;36:1920-1926. doi: 10. 1016/S0735-1097(00)00955-4.

[79] Grumbach IM, Heermann K, Figulla HR. Low prevalence of hepatitis C virus antibodies and RNA in patients with myocarditis and dilated cardiomyopathy. Cardiology 1998;90:75-78. doi: 10.1159/000006822.

[80] Teragaki M, Nishiguchi S, Takeuchi K, Yoshiyama M, Akioka K, Yoshikawa J. Prevalence of hepatitis $C$ virus infection among patients with hypertrophic cardiomyopathy. Heart Vessels 2003;18:167-170. doi: 10.1007/s00380003-0705-0.

[81] Amin J, Law MG, Bartlett M, Kaldor JM, Dore GJ. Causes of death after diagnosis of hepatitis $B$ or hepatitis $C$ infection: a large community-based linkage study. Lancet 2006;368:938-945. doi: 10.1016/S0140-6736(06)69374-4.

[82] Guiltinan AM, Kaidarova Z, Custer B, Orland J, Strollo A, Cyrus S, et al. Increased all-cause, liver, and cardiac mortality among hepatitis $C$ virusseropositive blood donors. Am J Epidemiol 2008;167:743-750. doi: 10. 1093/aje/kwm370.

[83] Lee $\mathrm{MH}$, Yang HI, Lu SN, Jen $\mathrm{CL}$, You SL, Wang LY, et al. Chronic hepatitis $\mathrm{C}$ virus infection increases mortality from hepatic and extrahepatic diseases: a community-based long-term prospective study. J Infect Dis 2012;206:469477. doi: $10.1093 /$ infdis/jis385.

[84] Younossi ZM, Braun WE, Protiva DA, Gifford RW Jr, Straffon RA. Chronic viral hepatitis in renal transplant recipients with allografts functioning for more than 20 years. Transplantation 1999;67:272-275. doi: 10.1097/00007890199901270-00015. 
[85] Fabrizi $F$, Dixit $V$, Messa $P$. Impact of hepatitis $C$ on survival in dialysis patients: a link with cardiovascular mortality? J Viral Hepat 2012;19:601607. doi: 10.1111/j.1365-2893.2012.01633.x.

[86] Vajdic CM, Marashi Pour S, Olivier J, Swart A, O'Connell DL, Falster MO, et al. The impact of blood-borne viruses on cause-specific mortality among opioid dependent people: An Australian population-based cohort study. Drug Alcohol Depend 2015;152:264-271. doi: 10.1016/j.drugalcdep.2015.03.026.

[87] Kristiansen MG, Løchen ML, Gutteberg T], Mortensen L, Eriksen BO, Florholmen J. Total and cause-specific mortality rates in a prospective study of community-acquired hepatitis $\mathrm{C}$ virus infection in northern Norway. J Viral Hepat 2011;18:237-244. doi: 10.1111/j.1365-2893.2010.01290.x.

[88] Brennan T, Shrank W. New expensive treatments for hepatitis C infection. JAMA 2014;312:593-594. doi: 10.1001/jama.2014.8897.

[89] Berenguer J, Rodríguez E, Miralles P, Von Wichmann MA, López-Aldeguer J, Mallolas J, et al. Sustained virological response to interferon plus ribavirin reduces non-liver-related mortality in patients coinfected with HIV and Hepatitis C virus. Clin Infect Dis 2012;55:728-736. doi: 10.1093/cid/cis500.
[90] Nahon $\mathrm{P}$, Bourcier V, Layese $\mathrm{R}$, Audureau $\mathrm{E}$, Cagnot $\mathrm{C}$, Marcellin $\mathrm{P}$, et al. Eradication of hepatitis $C$ virus infection in patients with cirrhosis reduces risk of liver and non-liver complications. Gastroenterology 2017;152:142156.e2. doi: 10.1053/j.gastro.2016.09.009

[91] Innes HA, McDonald SA, Dillon JF, Allen S, Hayes PC, Goldberg D, et al. Toward a more complete understanding of the association between a hepatitis C sustained viral response and cause-specific outcomes. Hepatology 2015;62:355-364. doi: 10.1002/hep.27766.

[92] Hsu YC, Ho HJ, Huang YT, Wang HH, Wu MS, Lin JT, et al. Association between antiviral treatment and extrahepatic outcomes in patients with hepatitis C virus infection. Gut 2015;64:495-503. doi: 10.1136/gutjnl2014-308163.

[93] Leone S, Prosperi M, Costarelli S, Nasta P, Maggiolo F, Di Giambenedetto S, et al. Incidence and predictors of cardiovascular disease, chronic kidney disease, and diabetes in HIV/HCV-coinfected patients who achieved sustained virological response. Eur J Clin Microbiol Infect Dis 2016;35:15111520. doi: $10.1007 / \mathrm{s} 10096-016-2692-y$. 